\title{
1 A giant cell enhancer achieves cell-type specificity through activation via TCP and repression 2 by Dof transcription factors
}

4 Lilan Hong ${ }^{1,2,5}$, Clint S. Ko ${ }^{2,3,5}$, S. Earl Kang ${ }^{4}$, Jose L. Pruneda-Paz ${ }^{4}$, Adrienne H. K. Roeder ${ }^{2 *}$

61 Institute of Nuclear Agricultural Sciences, Key Laboratory of Nuclear Agricultural Sciences of

7 Ministry of Agriculture and Zhejiang Province, College of Agriculture and Biotechnology, 8 Zhejiang University, Hangzhou 310058, China.

92 Weill Institute for Cell and Molecular Biology and School of Integrative Plant Science, Section 10 of Plant Biology, Cornell University, Ithaca, NY 14853 USA.

113 Present address: Laboratory of Morphogenesis, The Rockefeller University, New York, NY 1210065 USA.

134 Section of Cell and Developmental Biology, Division of Biological Sciences, University of

14 California San Diego, La Jolla, CA 92093, USA

155 Co-first authors

$16 *$ Correspondence: Adrienne Roeder (ahr75@cornell.edu)

17 Running title: Giant cell specific enhancer dissection

\section{Abstract}

20 Proper pattern formation relies on the tight coordination of cell fate specification and cell cycle

21 regulation in growing tissues. How this can be organized at enhancers that activate gene expression 22 necessary for differentiation is not well understood. One such example is the patterning of the 23 Arabidopsis thaliana sepal epidermis where giant cell fate specification is associated with the 24 endoreduplication cell cycle. Previously, we identified an enhancer region capable of driving giant 25 cell-specific expression. In this study, we use the giant cell enhancer as a model to understand the 26 regulatory logic that promotes cell-type specific expression. Our dissection of the enhancer 27 revealed that giant cell specificity is achieved primarily through the combination of two elements: 28 an activator and a repressor. TCP transcription factors are involved in activation of non-specific 29 expression throughout the epidermis with higher expression in endoreduplicated giant cells than 30 small cells. Dof transcription factors act via the second element to repress activity of the enhancer 
31 and limit expression to giant cells. Thus, we find that cell-type specific expression emerges from

32 the combined activities of two broadly acting enhancer elements.

35 Keywords: Arabidopsis, flower development, sepal, giant cell, enhancer, endoreduplication, Dof, TCP

\section{Introduction}

Plant and animal organs are composed of different types of cells that perform specialized roles. Cell-type specification is driven by the establishment of distinct patterns of gene expression, as has been confirmed recently by single-cell RNA-seq (Brady et al., 2007; Denyer et al., 2019; Jaitin et al., 2014; Lee and Schiefelbein, 2002; Ryu et al., 2019). Cell-type specific expression patterns are generally orchestrated through transcription factors binding to enhancers, short noncoding DNA sequences (Long et al., 2016). Enhancers typically contain clusters of transcription factor binding sites, acting as platforms to integrate information (Buecker and Wysocka, 2012). The spatial and temporal specificity of transcriptional regulation through enhancers has been extensively studied in several model organisms, including mouse, sea urchins, chicks, and fruit flies (Davidson, 2010; Spitz and Furlong, 2012). Recently, many enhancers have been identified in Arabidopsis thaliana (henceforth Arabidopsis) and other plants through whole genome methods, including hypersensitivity to DNase I (Oka et al., 2017; Yan et al., 2019; Zhu et al., 2015) and ATAC-seq (Ricci et al., 2019; Tannenbaum et al., 2018). However, relatively little is known about how individual enhancers function mechanistically in plants to generate cell-type specific expression patterns.

To elucidate the regulatory logic through which an individual enhancer drives cell-type specific expression, we used the Arabidopsis sepal giant cell model system. Sepals, the outermost floral organ, protect the inner androecium and gynoecium during floral development. On the abaxial epidermis of Arabidopsis sepals, epidermal pavement cells form patterns of two cell types: mitotically dividing small cells and elongated, endoreduplicating giant cells, which scatter between

59 the small cells (Figure 1B) (Roeder et al., 2010). Endoreduplication is a specialized cell cycle 60 wherein cells continue to grow and replicate their DNA but fail to undergo mitosis, generating 61 enlarged, polyploid cells (Traas et al., 1998). Thus, giant cells are a good model system for 
62 understanding the intersection of cell-type specification with cell division and growth. Giant cell

63 fate specification and differentiation is promoted by the epidermal specification pathway,

64 including Homeodomain-leucine zipper (HD-ZIP) Class IV transcription factors Arabidopsis

65 thaliana MERISTEM LAYER 1 (ATML1) and HOMEODOMAIN GLABROUS 11 (HDG11), as

66 well as intercellular signaling proteins DEFECTIVE KERNEL 1 (DEK1) and Arabidopsis

67 CRINKLY 4 (ACR4) (Roeder et al., 2012). The endomembrane trafficking protein SEC24A

68 restricts the formation of giant cells by modulating this pathway (Qu et al., 2014). Downstream of

69 the epidermal specification pathway, the SIAMESE family Cyclin Dependent Kinase Inhibitor

70 (CKI) LOSS OF GIANT CELLS FROM ORGANS (LGO, also known as SMR1) is required for

71 endoreduplication of giant cells (Meyer et al., 2017; Roeder et al., 2010; 2012; Schwarz and

72 Roeder, 2016). Giant cells affect sepal curvature (Roeder et al., 2012) and are hypothesized to play

73 a role in defense against pathogens based on transcriptomic analysis (Schwarz and Roeder, 2016).

74 Stochasticity in gene expression appears to be important for initiating the scattered pattern of giant

75 cells between smaller cells. Fluctuation of ATML1 expression to a high level during the G2 phase

76 of the cell cycle specifies giant cell fate (Meyer et al., 2017).

Our previous work described an enhancer region capable of driving giant cell-specific expression in sepals (Roeder et al., 2012). The region was identified based on an enhancer trap line (YJ158) in which the T-DNA was inserted $4.7 \mathrm{~kb}$ upstream of AT5G17700 (Figure 1A) (Eshed et al., 2004). AT5G17700 encodes a MATE efflux family protein. The giant cell-specific enhancer (hereafter referred to as the giant cell enhancer) was functionally defined as the $1024 \mathrm{bp}$ region immediately upstream of the enhancer trap T-DNA insertion; this region was sufficient for giantcell-specific expression in either orientation (Figure 1A) (Roeder et al., 2012). Expression of a reporter driven by the enhancer is regulated by ATML1 and the other members of the giant cell specification pathway (Roeder et al., 2012). In the leaf, the giant cell enhancer activates reporter expression both in giant epidermal pavement cells and leaf margin cells (Eshed et al., 2004; Roeder et al., 2012). The full $4.7 \mathrm{~kb}$ upstream region of AT5G17700 that includes the giant cell enhancer drives reporter expression in giant cells of young sepals as well as in other cell types (e.g. cells in petals and the style), suggesting that the giant cell enhancer is part of a larger regulatory region for AT5G17700 (Roeder et al., 2012). 
92 enhancer is comprised of an element promoting broad epidermal expression and a region that limits

93 this expression to highly endoreduplicated giant cells in the sepal. A genome-wide yeast one-

94 hybrid screen for transcription factors binding to the enhancer fragments identified Teosinte

95 branched1, Cycloidea, Proliferating cell factor (TCP) and DNA-binding one zinc finger (Dof)

96 transcription factors, among others. We show that TCP transcription factors are involved in

97 activating a broad epidermal pattern of expression. The Dof transcription factors broadly repress

98 expression, leading to giant cell-specific expression.

100 Results

101 Dissection of the giant cell enhancer delineates regions that drive broad epidermal expression 102 and limit expression to giant cells

103 To identify regulatory modules, the $1024 \mathrm{bp}$ giant cell enhancer was dissected into four 104 regions: 1 to 208 bp (Region 1), 209 to 449 bp (Region 2), 450 to 760 bp (Region 3), and 761 to $1051024 \mathrm{bp}$ (Region 4) (Figure 1A, and S1). Fragments containing these regions or combinations 106 thereof were cloned into a plasmid containing a minimal $35 \mathrm{~S}$ promoter (mini35S) driving a 107 nuclear-localized yellow fluorescent reporter $(3 \times$ Venus-N7) (Roeder, et al. 2012). Patterns of 108 Venus reporter expression were characterized in T1 transgenic lines from different constructs to 109 assess the capabilities of the different enhancer fragments to activate transcription. The full 1024 110 bp enhancer (Region 1-2-3-4, contained in pAR111) activated expression specifically in giant cells 111 in the sepal (Figure 1B), as previously shown (Roeder et al., 2012). Region 1 alone (in pAR280), 112 Region 4 alone (in $p A R 256$ ), or Regions 3 and 4 together (Region 3-4, in $p A R 258$ ) did not activate 113 reporter expression (Figure 1A and Figure S2). Region 2 alone (in $p A R 254$ ), Region 2 with Region 1143 (Region 2-3, in $p A R 261$ ), and Region 2 with Regions 3 and 4 (Region 2-3-4, in $p A R 260$ ) all 115 drove ubiquitous expression in the epidermis, not specific to giant cells (Figure 1A, D-F). Although 116 the reporter was expressed in all epidermal pavement cells for this broad epidermal expression 117 pattern, the expression level was about 2 fold higher in giant cells than small cells, as quantified 118 by mean fluorescence intensity of the reporter in the nucleus (Figure 1G). Regions 1, 2, and 3 119 together (Region 1-2-3, in $p A R 262$ ) were sufficient for driving reporter expression specifically in 120 endoreduplicated giant cells (Figure 1C). 
Regions 1 and 2 together (Region 1-2, in $p A R 257$ ) drove a varied expression pattern in

122 independent T1 transgenic lines, among which the majority showed giant cell specificity. To

123 further characterize the expression specificity of Region 1-2, we classified the expression pattern

124 of these T1 transgenic plants into three categories: (1) giant cell specific (type I) (Figure 2A); (2)

125 enhanced signal in giant cells with additional signal in the small cells at the sepal tip (type II, giant

126 cell enhanced) (Figure 2B); (3) broad epidermal signal (type III) (Figure 2C). We quantified the

127 percentage of $p A R 257$ (Region 1-2) independent T1 transgenic plants showing these three

128 expression patterns (47.8\% giant cell specific, $34.8 \%$ giant cell enhanced, and $17.4 \%$ epidermal),

129 and compared it with those of $p A R 111$ (Region 1-2-3-4), pAR254 (Region 2) and pAR261 (Region

130 2-3) plants. $p A R 111$ (Region 1-2-3-4) transgenic plants all showed giant cell specific signal. For 131 pAR254 (Region 2) and pAR261 (Region 2-3), the majority of the lines had type III, broad 132 epidermal signal, although occasionally, they showed type II, giant cell enhanced expression 133 pattern (Figure 2D). Together, these data suggest that Region 1-2 play an important role in 134 generating the giant cell specificity of enhancer activity. Region 2 is sufficient to produce broad 135 epidermal expression, while Region 1 is required for limiting expression to giant cells. In addition,

136 Region 3 and 4 play a small role in enhancing giant cell specificity when present in combination 137 with Region 1; therefore, we focused our further analysis on Regions 1 and 2.

\section{TCP transcription factors promote activity of the enhancer}

140 To identify transcription factors interacting with Regions 1 and 2 of the enhancer, we 141 performed a full-genome yeast one-hybrid screen with a library of 1956 transcription factors. We 142 analyzed Region 1, Region 2, and a 153 bp region overlapping the junction of these regions 143 separately (Figure S1); the overlap was intended to catch interactions that might be disrupted at 144 the boundary between Region 1 and Region 2. We identified 111 high-confidence (Table 1) and 14543 low-confidence interactions (Table S1) in total for all three assays (Datasets 1-3). We paid 146 particular attention to transcription factors that specifically bound one region and not the other 147 because they might play roles in driving the distinct expression patterns conferred by these regions. In the screen, several Class II CINCINNATA-like TCP transcription factors (TCP2, TCP3,

149 TCP4, TCP10) interacted with Region 2 and the overlap of the enhancer, but not Region 1. To test 150 for regulation of the enhancer by Class II TCPs, we crossed the full $1 \mathrm{~kb}$ enhancer reporter $(p A R 111)$ 151 to the jaw-1D mutant (Palatnik et al., 2003). The jaw-1D line overexpresses miR319a, a 
microRNA that targets $T C P 2, T C P 3, T C P 4, T C P 10$, and $T C P 24$, thus leading to downregulation

153 of these TCPs (Palatnik et al., 2003). In $p A R 111$ and jaw-1D F1 heterozygotes, sepals had fewer

154 cells expressing the reporter (Figure 3B and 3C), compared with sepals from $p A R 111$ and wild-

155 type (Col-0) F1 heterozygotes (Figure 3A and 3C). Knockdown of TCPs only affected the

156 expression of the pAR111 reporter and not the presence of giant cells in the sepal, as identified by

157 morphology (Figure 3B, PI stain). In $p A R 111 \times$ jaw-1D F1 hybrid sepals, the number of giant cells

158 was similar to that in $p A R 111 \times$ wild-type F1 sepals $(18.6 \pm 2.3$, mean $\pm \mathrm{SD}, \mathrm{n}=5$ in $p A R 111 \times$

159 jaw- $1 D \mathrm{~F} 1 ; 17 \pm 4.1$, mean $\pm \mathrm{SD}, \mathrm{n}=5$ in $p A R 111 \times$ wild-type $\mathrm{F} 1$; non-significant difference by $\mathrm{t}$

160 test); however, in jaw-1D $\times p A R 111 \mathrm{~F} 1$ sepals, most of these giant cells were not detectably

161 expressing the $p A R 111$ reporter (Figure 3B and 3C).

162 DNA affinity purification sequencing (DAP-seq) analysis (O'Malley et al., 2016) indicated

163 that TCP transcription factors bind to Region 2 (Figure S3) and throughout the intergenic region

164 upstream of AT5G17700. However, there are no obvious canonical TCP binding sites in Region 2.

165 We selected three sites with TGGG, which is half of the consensus TCP binding sequence, as

166 putative TCP binding sites in Region 2 (Figure S4). When all three of the TGGG sites in the Region

1672 reporter $p A R 254$ were mutated to TAAA ( $p L H 173)$, the reporter lines expressed almost no Venus

168 signal in sepal cells (Figure 3D and S5A). However, with extremely strong laser power, dim signal

169 could be detected in some pLH173 sepal cells (Figure S5B). This indicated that disruption of all

170 the TGGG sites significantly reduced transcriptional activity in Region 2 (Figure 3D). Thus, our

171 results suggest that binding of TCPs to Region 2 is critical for this region to activate expression.

173 Lowering the expression level increased giant cell specificity

174 While we were dissecting the enhancer into regions (Figures 1-2), we noticed that different 175 constructs required different laser intensity to generate the same fluorescence intensity of the 176 reporter in giant cells (as determined by giant cell signal saturation). We recorded the laser 177 intensity that different constructs required in order to reach the same giant cell fluorescence 178 intensity and found that $p A R 257$ (Region 1-2) needed much higher laser intensity than pAR254 179 (Region 2) alone to saturate the fluorescence in giant cells (Figure 3E), suggesting that Region 1 180 reduces transcriptional activity of Region 2.

181 Our analysis suggests that Region 1 reduces the activity of Region 2 and also limits reporter 182 expression mainly to giant cells. We hypothesized that these two functions of Region 1 are 
183 connected such that globally reducing expression activity would be sufficient to shift a broad

184 epidermal expression pattern toward a giant cell-specific expression pattern. To test this hypothesis,

185 we lowered the transcriptional activity of Region 2 by crossing the Region 2 reporter ( $p A R 254)$ to

186 the jaw-1D line. Plants heterozygous for both $p A R 254$ and jaw-1D (F1) had sepals that displayed

187 a giant cell-specific expression pattern (Figure 3G), instead of the broad epidermal expression

188 pattern in sepals heterozygous for $p A R 254$ alone (Figure $3 \mathrm{~F}$; $p A R 254 \times$ wild-type $\mathrm{F} 1$ heterozygote),

189 which confirmed that reducing Region 2 transcriptional activity increased the specificity of the

190 expression pattern to giant cells. These data are consistent with the hypothesis that Region 1 limits

191 the transcriptional activity driven by Region 2 to giant cells in part by reducing the overall

192 expression level, thus reducing the relatively low expression in small cells (Figure 1G) and

193 allowing only the relatively high expression in giant cells to persist.

Dof transcription factors repress expression of the enhancer by lowering the expression level and limiting it to giant cells.

We next searched for transcription factor binding sites in Region 1 responsible for

198 repressing expression, which give rise to giant cell specificity. Our yeast one-hybrid screen showed

199 that several Dof transcription factors bind to Region 1 and the overlap but not Region 2. Based on

200 the AthaMap website (http://www.athamap.de) transcription factor binding site prediction, a $24 \mathrm{bp}$

201 region 14 bp before the end of Region 1 contained three Dof transcription factor binding sites

202 (AAAG) (Noguero et al., 2013; Sani et al., 2018). We generated a reporter construct containing

203 Region 2 and extending 40 bp into the end of Region 1, which contained all three potential Dof

204 binding sites (Region 2+Dof in pAR307, Figure 4A and S4). As a control, we also generated a

205 construct containing Region 2 and $17 \mathrm{bp}$ at the end of Region 1, which excluded the Dof binding

206 sites ( $p A R 308$, Figure 4A and S4). The expression pattern of $p A R 307$ also varied among transgenic

207 lines. Categorizing the expression pattern showed that $p A R 307$ retained most of the giant cell

208 specific expression that Region 1-2 pAR257 has (Figure 4B). Removing the Dof binding sites

209 region led to an obvious shift in the expression pattern, with a majority of the $p A R 308$ plants

210 showing epidermal expression (Figure 4B), indicating the importance of the Dof binding sites in

211 generating the giant cell-specific expression pattern. Site-directed mutagenesis at these three

212 putative Dof binding sites in the 40 bp region (Region2-Dof mutant, $p L H 166$ ) reproduced the

213 epidermal expression pattern in $p A R 308$ (Figure 4B). There is also a trihelix site in the 24 bp Dof 
214 binding site region, and mutation of the trihelix site did not alter the expression pattern (data not

215 shown). We investigated the transcriptional activity of the enhancer fragments in $p A R 307, p A R 308$,

216 and $p L H 166$, by quantifying the laser intensity required for fluorescence to reach saturation in

217 giant cells. The shift of giant cell specific expression to epidermal expression was correlated with

218 an increase of reporter signal strength (detected with a lower power laser; Figure 4C), consistent

219 with our previous observations (Figure 3E).

220 Based on DAP-seq analysis, several Dof transcription factors bind to the $24 \mathrm{bp}$ Dof binding

221 site in Region 1 (Figure S6). The ones showing the highest binding affinity include: AtDOF2.2

222 (AT2G28810), HIGH CAMBIAL ACTIVITY2 (HCA2 AT5G62940), and AtDOF5.8 (AT5G66940).

223 We overexpressed each of the genes encoding these Dofs under the constitutive 35S promoter in

224 the pAR111 full length giant cell enhancer background to assess the impact of Dofs on enhancer

225 activity. Overexpression of each of these Dofs strongly decreased pAR111 expression in sepal

226 giant cells (Figure 5D-L) compared with the sepal giant cells from the $p A R 111$ control (Figure 5A-

227 C), indicating that Dof transcription factors repressed transcriptional activity of the giant cell

228 enhancer. Overexpression of the Dofs also severely inhibited sepal development, resulting in

229 shorter, narrow sepals in 35S::AtDOF2.2 and 35S::HCA2 (Figure 5D-E and G-H), and longer,

230 narrow sepals in 35S::AtDOF5.8 (Figure 5J-K). Even in these morphologically altered sepals,

231 giant cells were present, based on size and morphology. A couple of these giant cells expressed

232 low levels of the reporter, indicating that repression of $p A R 111$ expression was not due to the

233 absence of giant cells, but instead to repression of expression (arrowheads in Figure 5F, I, and L).

234 Thus, our results demonstrate that binding of Dofs to Region 1 reduce overall reporter expression

235 to confer giant cell-specific expression (Figure 4 and 5).

\section{Discussion}

In this study, we used giant cells as a model system to investigate how a cell type-specific 239 expression pattern is achieved and reported the dissection of an enhancer region driving a giant240 cell-specific expression pattern. This enhancer has a modular organization: Region 2 activated by

241 TCP transcription factors drives expression in all epidermal cells with higher levels of expression 242 in giant cells than small cells, while Region 1 is bound by Dof transcription factors to represses 243 expression, thus limiting expression to giant cells (Figure 6). This repression contributes to cell 244 type specificity due to the differences in expression level between giant cells and small cells driven 
by Region 2, which allows only the giant cell expression to remain after repression. Intriguingly, neither the activation nor the repression appears to be cell-type specific, yet the combination results in giant cell specificity.

Rough dissection (Figure 6C) indicated that transcription factors interacting with Region 2 are candidates for activating broad epidermal expression. The results from the large-scale yeast one-hybrid assay suggest 37 transcription factors showed high-confidence interaction with this region, including proteins from the TCP gene family (Table 1). The TCP family is divided into two main classes, based on differences in the TCP domains and binding sites. In general, class II TCP proteins are attributed to functions that inhibit plant cell division and growth, whereas class I proteins promote proliferation. For example, class II protein CINCINNATA (CIN) controls leaf surface curvature in Antirrhinum by making cells more sensitive to an arrest signal, inhibiting proliferation (Crawford et al., 2004; Nath et al., 2003). Interestingly, class II protein TCP4 regulates both density and branching of trichomes, another highly endoreduplicated cell type in Arabidopsis (Vadde et al., 2017; 2019). Class I TCP15 regulates expression of boundary-specific genes (Uberti-Manassero et al., 2011) and TCP20 promotes cell division (Li et al., 2005). Intriguingly, TCP15 also regulates endoreduplication in Arabidopsis (Zi-Yu et al., 2011). Moreover, specific repression of TCP15 by fusing to an EAR repressor domain has been reported to result in a loss of giant cells in the abaxial sepal epidermis (Uberti-Manassero et al., 2011). The TCP proteins identified from the screen, which bound to Region 2, (TCP2, TCP3, and TCP4) are all in the class II CINCINATA subfamily (Martín-Trillo and Cubas, 2010). As proteins in this subfamily act to repress cell proliferation, especially at the leaf margin, it is plausible, though untested, that these factors serve to coordinate activation of expression at the enhancer with the transition from proliferation to differentiation, since the giant-cell enhancer is only active after cells have stopped dividing (Roeder et al., 2012).

Among the yeast one-hybrid candidates, another group of transcription factors that might be involved in giant cell specific expression were the three HD-ZIP Class IVs: HDG11, ANL2, and GL2. HD-ZIP Class IV transcription factors are typically restricted to the L1 and act to specify epidermal cell type identity (Nakamura et al., 2006), making these strong candidates for activating epidermal expression at the enhancer. HDG11 has been shown to have a small role in promoting giant cell formation (Roeder et al., 2012). ATML1, a HD-ZIP Class IV not included in the yeast one-hybrid assay, has been shown to be required for giant cell patterning as well as specification 
276 of epidermal identity (Abe et al., 2003; Meyer et al., 2017; Roeder et al., 2012). We have 277 previously shown that overexpression of ATML1 is sufficient to create ectopic giant cells covering 278 the sepal and that these ectopic giant cells express the pAR111 full length giant cell enhancer 279 reporter (Meyer et al., 2017), suggesting ATML1 may be involved in activating enhancer activity. 280 Enhancer activity is downregulated but not completely absent in atmll mutants, consistent with a 281 role for ATML1 in activation of enhancer activity (Roeder et al., 2012). The canonical binding site 282 of ATML1 and other HD-ZIP Class IV transcription factors, the L1 box (TAAATGCA) (Abe et 283 al., 2001; Nakamura et al., 2006), does not appear in the enhancer sequence. However, we 284 speculate that HD-ZIP Class IV proteins may recognize another motif in the enhancer or interact 285 with other transcription factors. Non-L1-box regions have been shown to specify epidermal 286 identity; the promoter of ATML1 activates epidermis-specific expression even when its L1 box is deleted (Takada and Jurgens, 2007).

It is currently unclear what gives rise to higher expression in giant cells than small cells in the broad epidermal expression pattern generated by Region 2. Higher expression in giant cells could be caused by a combination of factors. One is that giant cells are endoreduplicated, generally reaching a ploidy of $16 \mathrm{C}$; thus, higher DNA content and associated increases in cell size could enhance expression (Robinson et al., 2018; Roeder et al., 2010). In trichomes, endoreduplication 293 has been shown to be important for the maintenance of cell identity (Bramsiepe et al., 2010). 294 However, as we have previously described, this giant cell enhancer is not strictly a marker of 295 ploidy and additional factors contributing to increased expression in giant cells are likely (Roeder 296 et al., 2012). HD-ZIP Class IV transcription factor ATML1 reaches higher levels of expression in 297 giant cells than small cells during their specification, which could initiate this pattern of higher 298 expression (Meyer et al., 2017). Finally, it is possible that TCPs or other factors binding to Region 2992 generate this difference in expression level. Further elucidating the cause of this difference in 300 expression will be an important future goal in understanding the relationship between 301 endoreduplication and cell identity in giant cells.

302 Giant cell specificity arises through the repressive activity of Region 1 (Figure 6C). Both 303 yeast one hybrid and DAP-seq results suggest that Dof transcription factors bind to Region 1 and 304 overexpression analyses and enhancer dissections suggest Dofs repress transcription to create giant 305 cell specificity. Region 1 alone does not activate any expression, suggesting it acts solely as a 306 repressor and detecting its output requires the activators bound to Region 2. Dof transcription 
307 factors bind AAAG sites in DNA through a single $\mathrm{N}$-terminal $\mathrm{C}_{2} \mathrm{C}_{2}$-zinc-finger like motif 308 (Noguero et al., 2013). Dof proteins interact more tightly with the DNA when two proximate 309 binding sites are present than they do with only one binding site (Sani et al., 2018), which is 310 consistent with the three nearby putative Dof sites in Region 1. There are 36 Dof family members 311 in Arabidopsis which tend to function redundantly (Gupta et al., 2015; Noguero et al., 2013; 312 Yanagisawa, 2002; 2015). Overexpression of each of the three Dof genes we tested was sufficient 313 to repress expression of the giant cell enhancer. Dof overexpression also altered sepal development, 314 making sepals narrow, and in most cases shorter, suggesting that these Dof genes are important for 315 sepal morphogenesis, not just regulation of this enhancer. Dofs have been shown to regulate many 316 developmental processes and environmental responses including seed germination, light response, 317 vascular cambium development, and cell division (Noguero et al., 2013). Dofs can act as either 318 activators or repressors in different contexts (Noguero et al., 2013). The Dof transcription factor 319 OPB1 promotes cell cycle entry by directly activating CYCLIN D3;3 and AtDOF2.3 which is 320 associated with replication (Skirycz et al., 2008). In seeds, DOF3.2 binds to the DELLA co321 repressor RGA-like 2 (RGL2) and DOF AFFECTING GERMINATION 1 (DAG1) binds to the 322 DELLA corepressor GA INSENSITIVE (GAI) to repress seed germination in the absence of 323 gibberellin (GA), linking Dofs with GA signaling (Boccaccini et al., 2014; Ravindran et al., 2017; 324 Ruta et al., 2020). This observation raises the possibility that the repressive activity conferred by 325 the Dofs could be mediated by co-repressors. Of the Dofs we tested, the functions of DOF2.2 326 (AT2G28810) remain unknown (Yanagisawa, 2015). HCA2/DOF5.6 (AT5G62940) promotes the 327 development of the vascular cambium and consequently the radial growth of the root (Guo et al., 328 2009; Miyashima et al., 2019). DOF5.8 (AT5G66940) regulates ANAC069 in response to abiotic 329 stress (He et al., 2020). In the future, it will be interesting to determine which Dofs are required 330 for the repressive activity of Region 1 in wild type sepals, since our overexpression analysis have 331 shown that all of three Dofs we tested, despite coming from different clades, were sufficient to 332 repress activity (Yanagisawa, 2002; 2015). Given the binding of multiple Dofs, including the three 333 we tested, to this enhancer region in the DAP-seq database, we expect multiple Dof proteins to act 334 redundantly in this role.

335 Enhancers tend to be conserved across closely related species because selection preserves 336 their function whereas nonfunctional intergenic sequences are not under selection and diverge 337 faster. This conservation has been used to identify enhancer sequences in non-coding DNA 
338 (Pennacchio et al., 2006). The giant cell enhancer includes a previously identified conserved 339 noncoding sequence (Haudry et al., 2013). Alignment of Region 1-2 enhancer sequences from six 340 species across the Brassicaceae family revealed that two of the three putative Dof binding sites we 341 identified are conserved, and all three of the putative TCP binding sites are conserved in 342 Arabidopsis lyrata, Cardamine hirsuta, Brassica rapa, Sisimbrium irio, and Eutrema salsugineum 343 (Figure S7). In the future, it will be interesting to determine whether these enhancers produce 344 similar expression patterns in these other species.

345 Previous studies in animals have often shown spatial restriction of enhancer activity is generated by broad activation combined with localized repression (Spitz and Furlong, 2012). For example, during early stages of sea urchin development, the endo16 gene is precisely expressed in the endoderm through broad activation in the embryo by the enhancer Region A combined with localized repression in the neighboring ectoderm by Regions $\mathrm{E}$ and $\mathrm{F}$ and localized repression in the neighboring skeletogenic mesenchyme by Region DC (Davidson, 2010). Likewise, in Drosophila the even-skipped (eve) stripe two enhancer is activated broadly by Bicoid (Bcd) and 352 Hunchback $(\mathrm{Hb})$, and narrowed to a precise stripe through repression by Giant (Gt) on the anterior 353 and Krüppel $(\mathrm{Kr})$ on the posterior (Stanojevic et al., 1991). Genetic analysis suggests a similar 354 regulatory logic is found in Arabidopsis during the establishment of the narrow band of 355 SHATTERPROOF (SHP) expression precisely at the valve margin through repression by 356 FRUITFULL (FUL) in valves and REPLUMLESS (RPL) in the replum (Ferrándiz et al., 2000; 357 Roeder et al., 2003). Our findings in the giant cell enhancer are distinct in that both the activator 358 and repressor do not appear to be spatially specific, and yet the combination gives rise to cell type specificity. Broad activation of the enhancer in all epidermal cells through a combination of TCP and other transcription factors likely including HD-ZIP Class IV transcription factors generates a pattern with high expression in giant cells and low expression in small cells. The Dof transcription

362 factors repress expression by lowering levels until the enhancer no longer activates expression in 363 small cells, and only expression in giant cells remains detectable (Figure 6). Thus, we suggest that 364 cell-type specificity can emerge from the combination of two modules neither of which is itself cell-type specific.

\section{Methods}




\section{Plant Growth}

370 Arabidopsis thaliana Col-0 plants were grown on Lambert Mix LM-111 soil in Percival growth

371 chambers at $22{ }^{\circ} \mathrm{C}$ with 24 hours fluorescent light $\left(\sim 100 \mu \mathrm{mol} \mathrm{m}{ }^{-2} \mathrm{~s}^{-1}\right)$ conditions. Seeds were

372 planted on soil and cold stratified for about two days before placing in the growth chambers.

\section{Giant cell enhancer dissection}

375 Cloning of the full length $1024 \mathrm{bp}$ enhancer construct pAR111 and verification that it was 376 sufficient to drive giant cell-specific expression in either orientation was previously described 377 (Roeder et al., 2012). This 1024 bp region was divided into four arbitrary regions with Region 1 378 falling closest to the downstream gene AT5G17700 and farthest from the original enhancer trap 379 insertion YJ158 (Figure 1). Enhancer fragments were tested for their activity in the orientation 380 they would have relative to downstream gene AT5G17700 such that Region 1 is closest to the 381 reporter gene.

382 We first cloned a gateway destination reporter vector (pSL12) so that we could rapidly 383 clone and assay the reporter expression patterns driven by fragments of the giant cell enhancer. 384 pSL12 contains a gateway site upstream of the -60 minimal promoter form $35 \mathrm{~S}$ and the $3 \times$ Venus385 N7 super-bright yellow-fluorescent nuclear-localized reporter in the pMLBart binary vector 386 backbone. pSL12 confers Basta resistance in plants and spectinomycin resistance in bacteria. To 387 create pSL12, the gateway site in which the NotI restriction site had been removed was amplified 388 with oAR505 and oXQ6 and cloned into pGEM-T Easy (Promega) to create pSL10. The gateway site was cut from pSL10 with $X h o \mathrm{I}$ and $\mathrm{KpnI}$ and cloned into $-603 \times$ Venus-N7-BJ36 (Roeder et al., 2012) to create pSL11. pSL11 was cut with NotI and the gateway $-603 \times$ Venus-N7 fragment was cloned into pMLBart to create pSL12.

393 Phusion (NEB) from the Arabidopsis thaliana genome BAC clone MAV3 or Col-0 genomic DNA

394 using the primers specified in Table S2 for each fragment. The primers sequences are listed in 395 Table S3. The PCR products were cloned into pENTR D TOPO (ThermoFisher) according to the 396 manufacturer's instructions to create the entry clones listed in Table S2. LR reactions 397 (ThermoFisher) between the entry clones and pSL12 generated the final constructs listed in Table 398 S2. Putative Dof and TCP sites were mutated through changes in the primer sequences. All 399 constructs were verified by sequencing the inserts. 
These constructs were transformed into Columbia (Col-0) plants through Agrobacteriummediated floral dipping and were selected for Basta Resistance. For most constructs the expression patterns in approximately $20 \mathrm{~T} 1$ transgenic plants were analyzed. Note the original pAR111

403 transgenic plants described in (Roeder et al., 2012) were in the Landsberg erecta (Ler) accession,

404 but for this project pAR111 was transformed into Col-0. Transformation of the empty vector pSL12 into plants generated no expression (Figure S2D). As typical with the independent insertion of the T-DNA into the genome (Schubert et al., 2004), we saw differences in expression level and sometimes pattern between different $\mathrm{T} 1$ lines as characterized in the results. However, within a single plant the expression pattern was similar across sepals. Likewise the expression pattern was consistent in subsequent $\mathrm{T} 2$ and $\mathrm{T} 3$ generations for those lines examined.

\section{Confocal Microscopy}

412 To minimize the morphological or gene expression variability caused by different plant vitality, 413 the 12 th to 25 th flowers on the main stem were used for observation (Hong et al., 2016). Mature 414 sepals (stage 14 according to (Smyth et al., 1990)) were dissected from the flowers with tweezers 415 and needles and stained for 15 minutes in propidium iodide (PI; $0.15 \mathrm{mg} / \mathrm{ml}$ in water), mounted 416 on slides in $0.01 \%$ triton X-100 under a cover slip, and imaged with a Zeiss 710 confocal laser 417 scanning microscope. A $514 \mathrm{~nm}$ excitation laser was used to excite both the fluorophores. The $4183 \times$ Venus-N7 enhancer reporter signal was collected between 519 to $566 \mathrm{~nm}$, while the PI signal 419 was collected between 603-650 nm. Images were taken using 10X (Plan-APOCROMAT NA = 4200.45 air) or 20X (Plan-APOCROMAT NA = 1.0 water dipping) objective lenses. Different T1 421 transgenic lines have different levels of expression likely due to effects of the position of insertion 422 of the T-DNA. For the experiments in Figures 1, 2, and 4 we varied the laser power to achieve 423 saturation of the reporter in a few of the brightest giant cell nuclei (the other settings including 424 gain were kept the same). This allowed us to compare reporter expression between cells while 425 keeping the expression level in giant cells relatively constant (ranges of laser power used are 426 reported in Figure 3E). In contrast, Figure S5 shows the same sepal imaged with different laser 427 powers (3\% and $40 \%$ as indicated in the figure), to detect very low levels of expression. For most 428 images the maximum intensity projection is shown. For Figure 5C,F,I, and L the image was 429 volume rendered in MorphoGraphX and subsequently Auto Contrast was used in photoshop to 430 visualize the epidermal cell layer without the underlying layers. 


\section{Quantitative Image Processing}

433 FIJI (https://fiji.sc) with the Costanza plugin (http://home.thep.lu.se/ henrik/Costanza/) was used

434 to quantify the fluorescence intensity and size of nuclei expressing pAR254. In the images used,

435 the fluorescence intensity of the reporter in the nuclei was not saturated. The .lsm stack image 436 from the microscope was opened in FIJI. The color of Channel 1 (with the reporter expression)

437 was converted to greys using the Channels tool. The channels were split using Split Channels. The 438 maximum intensity projection of Channel 1 (reporter expression) was created with $\mathrm{Z}$ project. The 439 maximum intensity projection image was analyzed with the Costanza plugin with the following 440 settings. In the general menu, "Mark intensity plateau with single maximum" was checked as were 441 "Mark cell centers. Marker pixel radius: 3", Display basins of attractions (BOA)", and "Display 442 basins of attractions according to measured intensity." In the pre-processor queue, "Background 443 extraction" with an intensity threshold of 20 was executed first followed by "Mean filter" with 444 radius 0.1 and number of times 10. In the post-processor, "BOA remover" with a size threshold of 44510 and an intensity threshold of 10 was executed first followed by a "BOA merger" with a radius 446 of 15. Use ImageJ stack calibration was used for scaling. The results were analyzed in Microsoft 447 Excel. Giant cells have enlarged nuclei, so a threshold of $100 \mu^{2}$ was used to separate giant cell 448 from small cell nuclei.

450 To count the nuclei number in Figure 3C, we kept the image settings including the laser power and 451 gain the same when imaging the sepals for both $p A R 111 \times \mathrm{Col} \mathrm{F1}$ and $p A R 111 \times j a w-1 D \mathrm{TCP}$ 452 knock down F1. Images were processed with maximal intensity projection using the Zeiss Zen 453 software and nuclei which showed saturation of the reporter signals were counted as giant cell 454 nuclei.

\section{Statistics}

457 Two-tailed students T-tests were used for pairwise comparisons.

\section{High Throughput Yeast-One-Hybrid Screen}

460 Yeast-one-hybrid screens were conducted with a nearly genome-wide transcription factor 461 collection arrayed in 384 well plates (Pruneda-Paz et al., 2014) according to the protocol in (Li et 
al., 2019) using a luciferase reporter (Bonaldi et al., 2017). Bait plasmids were created through LR reactions of entry clones containing Region 1, Region 2 or a region overlapping the junction between Regions 1 and 2 into the pY1-gLUC59_GW yeast reporter plasmid (Table S4). The resulting constructs were integrated into the URA3 locus on the chromosome of the yeast strain YM4271.

\section{Genetic interaction with jaw-1D}

469 The jaw-1D mutant (CS6948) was ordered from the Arabidopsis Biological Resource Center 470 (ABRC). The homozygous jaw-1D mutant was crossed to pAR111 plants and to pAR254 plants.

471 The expression patterns were analyzed in the F1 generation which were heterozygous for the 472 reporter and the jaw-1D dominant mutant. The expression patterns were compared with the F1 473 generation of the cross of each reporter with Col-0 wild type as a control.

\section{Dof overexpression}

476 Entry clones containing Dof family member cDNAs were ordered from the ABRC: TOPO-U09G04 (AT2G28810), TOPO-U20-E12 (AT5G62940), and TOPO-U13-H01 (AT5G66940).

478 Through LR reactions these were recombined into the binary $35 \mathrm{~S}$ destination vector pK7WG2 to 479 make pLH160 (35S::AT2G28810 CDS), pLH162 (35S::AT5G62940 CDS), and pLH163 480 (35S::AT5G66940 CDS). These constructs were transformed into pAR111 (in Col-0) plants 481 through agrobacterium-mediated floral dipping and were selected for kanamycin resistance.

\section{Flower pictures}

484 Images of flowers were taken on a Zeiss Stemi 2000-C stereomicroscope with a Cannon Powershot 485 A640 digital camera.

\section{DAP-seq database analysis}

488 The $\mathrm{C}_{2} \mathrm{C}_{2}$-Dof and TCP transcription factor families DAP-seq data was analyzed from the Plant 489 Cistrome Database (http://neomorph.salk.edu/dev/pages/shhuang/dap_web/pages/index.php 490 (O’Malley et al., 2016)) using the Genome Browser to examine the giant cell enhancer region on 491 chromosome 5 coordinates 5837111-5837559 for Region 1-2. 


\section{Alignment of the giant cell enhancer from Brassicaceae species}

494 A conserved noncoding sequence (Chr5:5,837,330-5,837,417) has been identified among 495 Brassicaceae species (Haudry et al., 2013) overlapping with Region 2 of the giant cell enhancer 496 (http://mustang.biol.mcgill.ca:8885/cgi-bin/hgGateway). To examine sequence conservation of

497 Regions 1 and 2 of the enhancer and the putative Dof and TCP binding sites we aligned the 498 corresponding sequences from Arabidopsis thaliana, Arabidopsis lyrata, Cardamine hirsuta 499 (CoGe id 36106 Cardamine hirsute v1 unmasked Chromosome 6 18239653-18239154), Brassica 500 rapa (COGE id 24668 Brasica DB Chr unmasked v1.5 chromosome A10 $11517566-11517500$ and A02 3259372-3259603), Eutrema parvulum (formerly Thellungiella parvula 12384 UIUC unmasked v2 chomosome 6-6 5884609-5883951), Eutrema salsugineum (Id 19492 JGI unmasked 6007159-6007397), Sisimbrium irio (Id 20245 VEGI unmasked vVEGI 2.5 Chromosome scaffold_57 2159183-2159617). All sequences were checked that they fell in syntenic regions upstream of a homolog of AT5G17700. The sequences were aligned with Clustal Omega (https://www.ebi.ac.uk/Tools/msa/clustalo/) and the alignments were formatted and displayed with Boxshade (https://embnet.vital-it.ch/software/BOX form.html). Alignments were adjusted slightly by hand around gaps and the ends of sequences were trimmed or extended to give the best alignment (Figure S7).

\section{Accession Numbers}

512 Giant cell enhancer associated MATE efflux family protein, AT5G17700.

513 jaw-1D seed (CS6948) and associated gene miR319a (AT4G23713)

514 Dof family members analyzed: AT2G28810, AT5G62940, AT5G66940

\section{Distribution of Materials and Data}

517 Requests for materials and data should be addressed to Adrienne H. K. Roeder 518 (ahr75@cornell.edu).

\section{Author Contributions}

521 Conception and design of experiments: L.H., C.S.K., A.H.K.R.

522 Giant cell enhancer dissection experiments and analysis: L.H., C.S.K., A.H.K.R.

523 High throughput yeast-one-hybrid screen: S.E.K., J.L.P.-P. 
524 Writing of the manuscript: L.H., A.H.K.R.

525 Revising and editing of the manuscript: L.H., C.S.K., J.L.P.-P., A.H.K.R.

\section{Acknowledgements}

528 We thank Joseph Cammarata, Frances Clark, Kate Harline, Shuyao Kong, Xiaobo Zhao and Ming

529 Zhou for critical reading and comments on the manuscript. We thank Samuel Leiboff and Dana

530 Robinson for technical assistance in cloning constructs for this project.

531 This work was supported by NSF IOS Plant, Fungal, and Microbial Developmental Mechanisms

532 grants IOS-1256733 (AHKR) and IOS-1553030 (AKHR), NSF IOS 1755452 (JLPP), NSF MCB

5331158254 (JLPP) and NIH R01GM056006 (JLPP). No conflicts of interest declared.

References

Abe, M., Takahashi, T., and Komeda, Y. (2001). Identification of a cis-regulatory element for L1 layer-specific gene expression, which is targeted by an L1-specific homeodomain protein. Plant $\mathrm{J}$ 538 26, 487-494.

Abe, M., Katsumata, H., Komeda, Y., and Takahashi, T. (2003). Regulation of shoot epidermal cell differentiation by a pair of homeodomain proteins in Arabidopsis. Development 130, 635-

541643.

Boccaccini, A., Santopolo, S., Capauto, D., Lorrai, R., Minutello, E., Serino, G., Costantino, P., and Vittorioso, P. (2014). The DOF Protein DAG1 and the DELLA Protein GAI Cooperate in 544 Negatively Regulating the AtGA3ox1 Gene. Mol Plant 7, 1486-1489.

545 Bonaldi, K., Li, Z., Kang, S.E., Breton, G., and Pruneda-Paz, J.L. (2017). Novel cell surface 546 luciferase reporter for high-throughput yeast one-hybrid screens. Nucleic Acids Res 45, e157.

547 Brady, S.M., Orlando, D.A., Lee, J.-Y., Wang, J.Y., Koch, J., Dinneny, J.R., Mace, D., Ohler, 548 U., and Benfey, P.N. (2007). A high-resolution root spatiotemporal map reveals dominant 549 expression patterns. Science 318, 801-806.

550 Bramsiepe, J., Wester, K., Weinl, C., Roodbarkelari, F., Kasili, R., Larkin, J.C., Hülskamp, M., 551 and Schnittger, A. (2010). Endoreplication controls cell fate maintenance. PLoS Genet 6 , $552 \mathrm{e} 1000996$.

553 Buecker, C., and Wysocka, J. (2012). Enhancers as information integration hubs in development: 554 lessons from genomics. Trends Genet 28, 276-284. 
Crawford, B.C.W., Nath, U., Carpenter, R., and Coen, E.S. (2004). CINCINNATA controls both cell differentiation and growth in petal lobes and leaves of Antirrhinum. Plant Phys 135, 244253.

Davidson, E.H. (2010). Chapter 2 cis-Regulatory modules, and the structure/function basis of regulatory logic. In The Regulatory Genome, (Elsevier), pp. 31-86.

Denyer, T., Ma, X., Klesen, S., Scacchi, E., Nieselt, K., and Timmermans, M.C.P. (2019). Spatiotemporal Developmental Trajectories in the Arabidopsis Root Revealed Using HighThroughput Single-Cell RNA Sequencing. Dev Cell 48, 840-852.e5.

Eshed, Y., Izhaki, A., Baum, S.F., Floyd, S.K., and Bowman, J.L. (2004). Asymmetric leaf development and blade expansion in Arabidopsis are mediated by KANADI and YABBY activities. Development 131, 2997-3006.

Ferrándiz, C., Liljegren, S.J., and Yanofsky, M.F. (2000). Negative regulation of the SHATTERPROOF genes by FRUITFULL during Arabidopsis fruit development. Science 289, 436-438.

Guo, Y., Qin, G., Gu, H., and Qu, L.-J. (2009). Dof5.6/HCA2, a Dof Transcription Factor Gene, Regulates Interfascicular Cambium Formation and Vascular Tissue Development in Arabidopsis. Plant Cell 21, 3518-3534. (2015). Insights into structural and functional diversity of Dof (DNA binding with one finger) transcription factor. Planta 241, 549-562.

Haudry, A., Platts, A.E., Vello, E., Hoen, D.R., Leclercq, M., Williamson, R.J., Forczek, E., Joly-Lopez, Z.E., Steffen, J.G., Hazzouri, K.M., et al. (2013). An atlas of over 90,000 conserved noncoding sequences provides insight into crucifer regulatory regions. Nat Genet 45, 891-898.

He, L., Su, C., Wang, Y., and Wei, Z. (2020). ATDOF5.8 protein is the upstream regulator of ANAC069 and is responsive to abiotic stress. Biochimie 110, 17-24.

Hong, L., Dumond, M., Tsugawa, S., Sapala, A., Routier-Kierzkowska, A.-L., Zhou, Y., Chen, C., Kiss, A., Zhu, M., Hamant, O., et al. (2016). Variable cell growth
development through spatiotemporal averaging. Dev Cell 38, 15-32. free decomposition of tissues into cell types. Science 343, 776-779. determined by lateral inhibition with feedback. Plant Cell 14, 611-618. 
Li, Z., Bonaldi, K., Kang, S.E., and Pruneda-Paz, J.L. (2019). High-Throughput Yeast OneHybrid Screens Using a Cell Surface gLUC Reporter. Current Protocols in Plant Biology 4, e20086.

Long, H.K., Prescott, S.L., and Wysocka, J. (2016). Ever-Changing Landscapes: Transcriptional Enhancers in Development and Evolution. Cell 167, 1170-1187.

Martín-Trillo, M., and Cubas, P. (2010). TCP genes: a family snapshot ten years later. Trends Plant Sci 15, 31-39.

Meyer, H.M., Teles, J., Formosa-Jordan, P., Refahi, Y., San-Bento, R., Ingram, G., Jönsson, H., Locke, J.C.W., and Roeder, A.H.K. (2017). Fluctuations of the transcription factor ATML1 generate the pattern of giant cells in the Arabidopsis sepal. eLife 6, e19131.

Miyashima, S., Roszak, P., Sevilem, I., Toyokura, K., Blob, B., Heo, J.-O., Mellor, N., Helppositional cues to prime cambial growth. Nature 565, 490-494.

604 Nakamura, M., Katsumata, H., Abe, M., Yabe, N., Komeda, Y., Yamamoto, K.T., and

605 Takahashi, T. (2006). Characterization of the class IV homeodomain-Leucine Zipper gene family 606 in Arabidopsis. Plant Phys 141, 1363-1375.

607 Nath, U., Crawford, B.C.W., Carpenter, R., and Coen, E.S. (2003). Genetic control of surface curvature. Science 299, 1404-1407.

Noguero, M., Atif, R.M., Ochatt, S., and Thompson, R.D. (2013). The role of the DNA-binding One Zinc Finger (DOF) transcription factor family in plants. Plant Sci 209, 32-45.

Oka, R., Zicola, J., Weber, B., Anderson, S.N., Hodgman, C., Gent, J.I., Wesselink, J.-J., Springer, N.M., Hoefsloot, H.C.J., Turck, F., et al. (2017). Genome-wide mapping of $61418,137$.

615 O’Malley, R.C., Huang, S.-S.C., Song, L., Lewsey, M.G., Bartlett, A., Nery, J.R., Galli, M., 616 Gallavotti, A., and Ecker, J.R. (2016). Cistrome and Epicistrome Features Shape the Regulatory 617 DNA Landscape. Cell 165, 1280-1292.

618 Palatnik, J.F., Allen, E., Wu, X., Schommer, C., Schwab, R., Carrington, J.C., and Weigel, D. 619 (2003). Control of leaf morphogenesis by microRNAs. Nature 425, 257-263.

620 Pennacchio, L.A., Ahituv, N., Moses, A.M., Prabhakar, S., Nobrega, M.A., Shoukry, M., 621 Minovitsky, S., Dubchak, I., Holt, A., Lewis, K.D., et al. (2006). In vivo enhancer analysis of 622 human conserved non-coding sequences. Nature 444, 499-502.

623 Pruneda-Paz, J.L., Breton, G., Nagel, D.H., Kang, S.E., Bonaldi, K., Doherty, C.J., Ravelo, S., 624 Galli, M., Ecker, J.R., and Kay, S.A. (2014). A Genome-Scale Resource for the Functional 625 Characterization of Arabidopsis Transcription Factors. Cell Reports 8, 622-632. 
Qu, X., Chatty, P.R., and Roeder, A.H.K. (2014). Endomembrane trafficking protein SEC24A regulates cell size patterning in Arabidopsis. Plant Phys 166, 1877-1890.

628 Ravindran, P., Verma, V., Stamm, P., and Kumar, P.P. (2017). A Novel RGL2-DOF6 Complex Contributes to Primary Seed Dormancy in Arabidopsis thaliana by Regulating a GATA Transcription Factor. Mol Plant 10, 1307-1320.

Ricci, W.A., Lu, Z., Ji, L., Marand, A.P., Ethridge, C.L., Murphy, N.G., Noshay, J.M., Galli, M., Mejía-Guerra, M.K., Colomé-Tatché, M., et al. (2019). Widespread long-range cis-regulatory elements in the maize genome. Nature Plants 5, 1237-1249.

634 Robinson, D.O., Coate, J.E., Singh, A., Hong, L., Bush, M.S., Doyle, J.J., and Roeder, A.H.K. 635 (2018). Ploidy and Size at Multiple Scales in the Arabidopsis Sepal. Plant Cell 30, 2308-2329.

Roeder, A.H.K., Chickarmane, V., Cunha, A., Obara, B., Manjunath, B.S., and Meyerowitz, E.M. (2010). Variability in the control of cell division underlies sepal epidermal patterning in Arabidopsis thaliana. PLoS Biol 8, e1000367.

Roeder, A.H.K., Cunha, A., Ohno, C.K., and Meyerowitz, E.M. (2012). Cell cycle regulates cell type in the Arabidopsis sepal. Development 139, 4416-4427. homeodomain protein in patterning the Arabidopsis fruit. Curr Biol 13, 1630-1635.

Ruta, V., Longo, C., Lepri, A., De Angelis, V., Occhigrossi, S., Costantino, P., and Vittorioso, P.

645 Ryu, K.H., Huang, L., Kang, H.M., and Schiefelbein, J. (2019). Single-Cell RNA Sequencing 646 Resolves Molecular Relationships Among Individual Plant Cells. Plant Phys 179, 1444-1456.

647 Sani, H.M., Hamzeh-Mivehroud, M., Silva, A.P., Walshe, J.L., Mohammadi, S.A., Rahbar648 Shahrouziasl, M., Abbasi, M., Jamshidi, O., Low, J.K., Dastmalchi, S., et al. (2018). Expression, 649 purification and DNA-binding properties of zinc finger domains of DOF proteins from

650 Arabidopsis thaliana. Tabriz University of Medical Sciences 8, 167-176.

651 Schubert, D., Lechtenberg, B., Forsbach, A., Gils, M., Bahadur, S., and Schmidt, R. (2004). 652 Silencing in Arabidopsis T-DNA Transformants: The Predominant Role of a Gene-Specific 653 RNA Sensing Mechanism versus Position Effects. Plant Cell 16, 2561-2572.

654 Schwarz, E.M., and Roeder, A.H.K. (2016). Transcriptomic Effects of the Cell Cycle Regulator 655 LGO in Arabidopsis Sepals. Front Plant Sci 7, 635-22.

656 Skirycz, A., Radziejwoski, A., Busch, W., Hannah, M.A., Czeszejko, J., Kwaśniewski, M., 657 Zanor, M.-I., Lohmann, J.U., De Veylder, L., Witt, I., et al. (2008). The DOF transcription factor 658 OBP1 is involved in cell cycle regulation in Arabidopsis thaliana. Plant J 56, 779-792.

659 Smyth, D.R., Bowman, J.L., and Meyerowitz, E.M. (1990). Early flower development in 660 Arabidopsis. Plant Cell 2, 755-767. 
661 Spitz, F., and Furlong, E.E.M. (2012). Transcription factors: from enhancer binding to

662 developmental control. Nat Rev Genet 13, 613-626.

663 Stanojevic, D., Small, S., and Levine, M. (1991). Regulation of a segmentation stripe by

664 overlapping activators and repressors in the Drosophila embryo. Science 254, 1385-1387.

665 Takada, S., and Jurgens, G. (2007). Transcriptional regulation of epidermal cell fate in the 666 Arabidopsis embryo. Development 134, 1141-1150.

667 Tannenbaum, M., Sarusi-Portuguez, A., Krispil, R., Schwartz, M., Loza, O., Benichou, J.I.C., 668 Mosquna, A., and Hakim, O. (2018). Regulatory chromatin landscape in Arabidopsis thaliana 669 roots uncovered by coupling INTACT and ATAC-seq. Plant Methods 14, 113.

670 Traas, J., Hülskamp, M., Gendreau, E., and Höfte, H. (1998). Endoreduplication and

671 development: rule without dividing? Curr Opin in Plant Biol 1, 498-503.

672 Uberti-Manassero, N.G., Lucero, L.E., Viola, I.L., Vegetti, A.C., and Gonzalez, D.H. (2011).

673 The class I protein AtTCP15 modulates plant development through a pathway that overlaps with

674 the one affected by CIN-like TCP proteins. J Exp Bot 63, 809-823.

675 Vadde, B.V.L., Challa, K.R., and Nath, U. (2017). The TCP4 transcription factor regulates 676 trichome cell differentiation by directly activating GLABROUS INFLORESCENCE STEMSin 677 Arabidopsis thaliana. Plant J 93, 259-269.

678 Vadde, B.V.L., Challa, K.R., Sunkara, P., Hegde, A.S., and Nath, U. (2019). The TCP4

679 Transcription Factor Directly Activates TRICHOMELESS1 and 2and Suppresses Trichome

680 Initiation. Plant Phys 181, 1587-1599.

681 Yan, W., Chen, D., Schumacher, J., Durantini, D., Engelhorn, J., Chen, M., Carles, C.C., and

682 Kaufmann, K. (2019). Dynamic control of enhancer activity drives stage-specific gene

683 expression during flower morphogenesis. Nat Commun 10, 1705.

684 Yanagisawa, S. (2002). The Dof family of plant transcription factors. Trends Plant Sci 7, 555685560.

686 Yanagisawa, S. (2015). Structure, Function, and Evolution of the Dof Transcription Factor 687 Family (Elsevier Inc.).

688 Zhu, B., Zhang, W., Zhang, T., Liu, B., and Jiang, J. (2015). Genome-Wide Prediction and 689 Validation of Intergenic Enhancers in Arabidopsis Using Open Chromatin Signatures. Plant Cell $690 \quad 27,2415-2426$.

691 Zi-Yu, L., Bin, L., and Ai-Wu, D. (2011). The Arabidopsis Transcription Factor AtTCP15 692 Regulates Endoreduplication by Modulating Expression of Key Cell-cycle Genes. Mol Plant 5, $693270-280$. 
bioRxiv preprint doi: https://doi.org/10.1101/2020.08.28.270454; this version posted November 14,2020 . The copyright holder for this preprint (which was not certified by peer review) is the author/funder, who has granted bioRxiv a license to display the preprint in perpetuity. It is made available under aCC-BY-NC 4.0 International license.

\section{Supplemental Information}

696 Dataset S1: Yeast-one-hybrid results for Region 1.

697 Dataset S2: Yeast-one-hybrid results for Region 2.

698 Dataset S3: Yeast-one-hybrid results for the overlap between Regions 1 and 2.

699 
bioRxiv preprint doi: https://doi.org/10.1101/2020.08.28.270454; this version posted November 14,2020 . The copyright holder for this preprint (which was not certified by peer review) is the author/funder, who has granted bioRxiv a license to display the preprint in perpetuity. It is made available under aCC-BY-NC 4.0 International license.
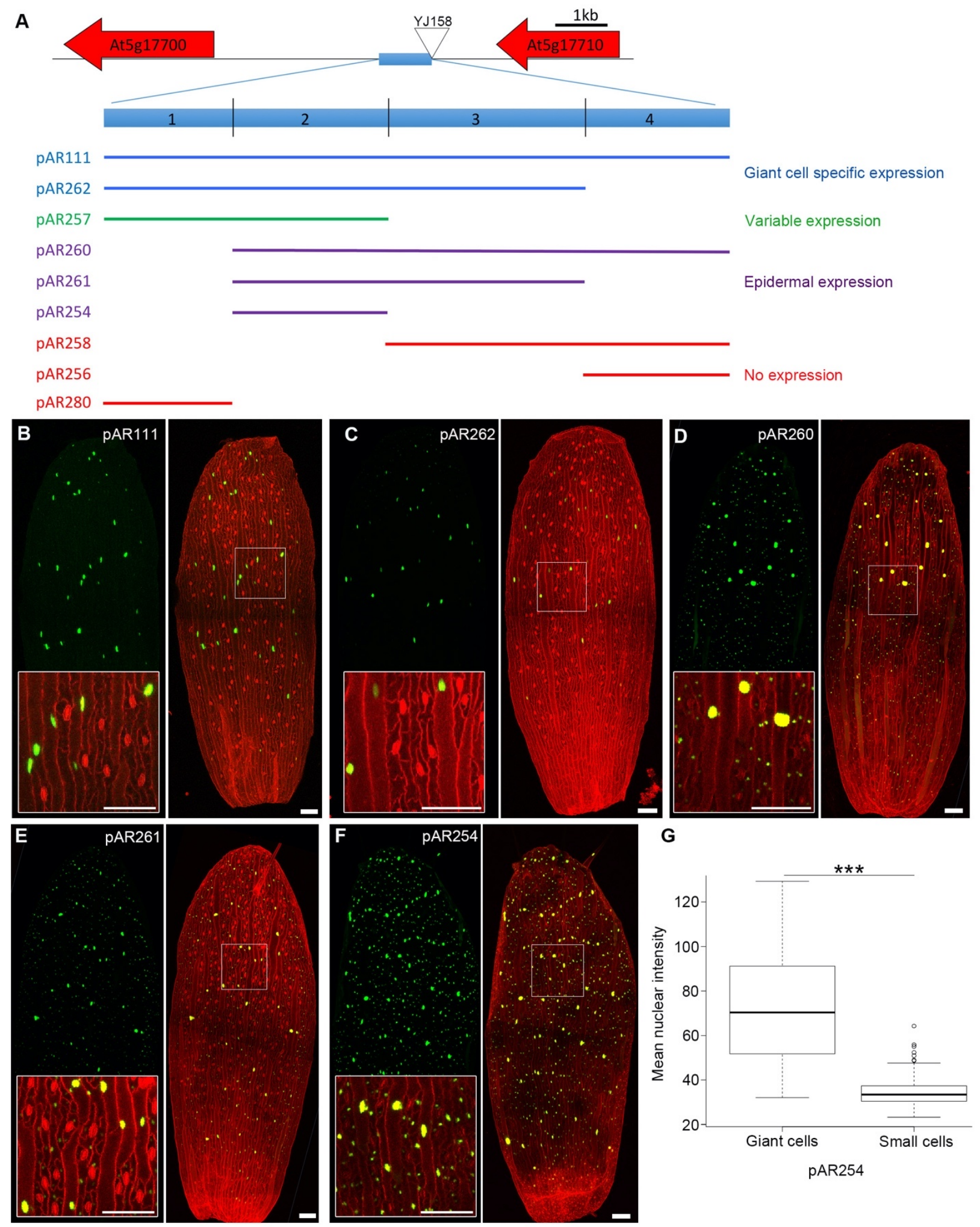

Figure 1. Dissection of $1 \mathrm{~kb}$ giant cell enhancer.

(A) The giant cell enhancer is a $1 \mathrm{~kb}$ sequence $3.2 \mathrm{~kb}$ upstream of $A T 5 G 17700$, a gene encoding a MATE efflux family protein. The $1 \mathrm{~kb}$ enhancer was originally identified because it flanked the YJ158 enhancer 
trap T-DNA insertion (triangle), which produced the same giant cell-specific expression pattern. The enhancer was divided into four regions. Different constructs containing different regions of the enhancer for testing enhancer elements are diagrammed below. Reporter lines with these constructs were tested for their ability to produce expression of the nuclear localized $3 \times$ Venus-N7 reporter under a -60 minimal $35 \mathrm{~S}$ promoter. Enhancer fragments in the different reporter lines are color coded with their expression patterns: blue denotes giant cell-specific expression, purple for epidermal expression, green for expression patterns that vary between giant cell-specific and broad epidermal independent T1 lines (further classified in Figure 2), and red for no expression.

(B-F) Confocal images of stage 14 sepals from different reporter lines. Images on the left, $3 \times$ Venus (green) marking the nuclei of cells expressing the reporter; Images on the right, $3 \times$ Venus (green) signals merged with propidium iodide (PI, red) stained cell wall signals. Insets overlapping the base of the green channel images, show magnified views of the cells outlined with the box. Expression of the $3 \times$ Venus is restricted to giant cells in reporter lines $p A R 111$ and $p A R 262(\mathrm{~B}, \mathrm{C})$. The reporter has a broader expression in $p A R 260$, $p A R 261$ and $p A R 254(\mathrm{D}, \mathrm{E}, \mathrm{F})$. Note that stomatal guard cells stain as red oblongs. Scale bars: $100 \mu \mathrm{m}$.

(G) Mean fluorescent intensity of the $3 \times$ Venus reporter in giant cell nuclei versus small cell nuclei of pAR254 sepals, which is expressed in a broad epidermal pattern. Note that the expression (intensity) is about 2-fold higher in giant cell nuclei. The boxes extend from the lower to upper quartile values of the data, with a line at the median. The whiskers extend past 1.5 of the interquartile range. $* * * p<0.001$, significant difference by two tailed t-test, $\mathrm{p}=4.29 \mathrm{E}-13 ; \mathrm{n}=210$ small cells and 48 giant cells.

See also Figures S1 and S2. 

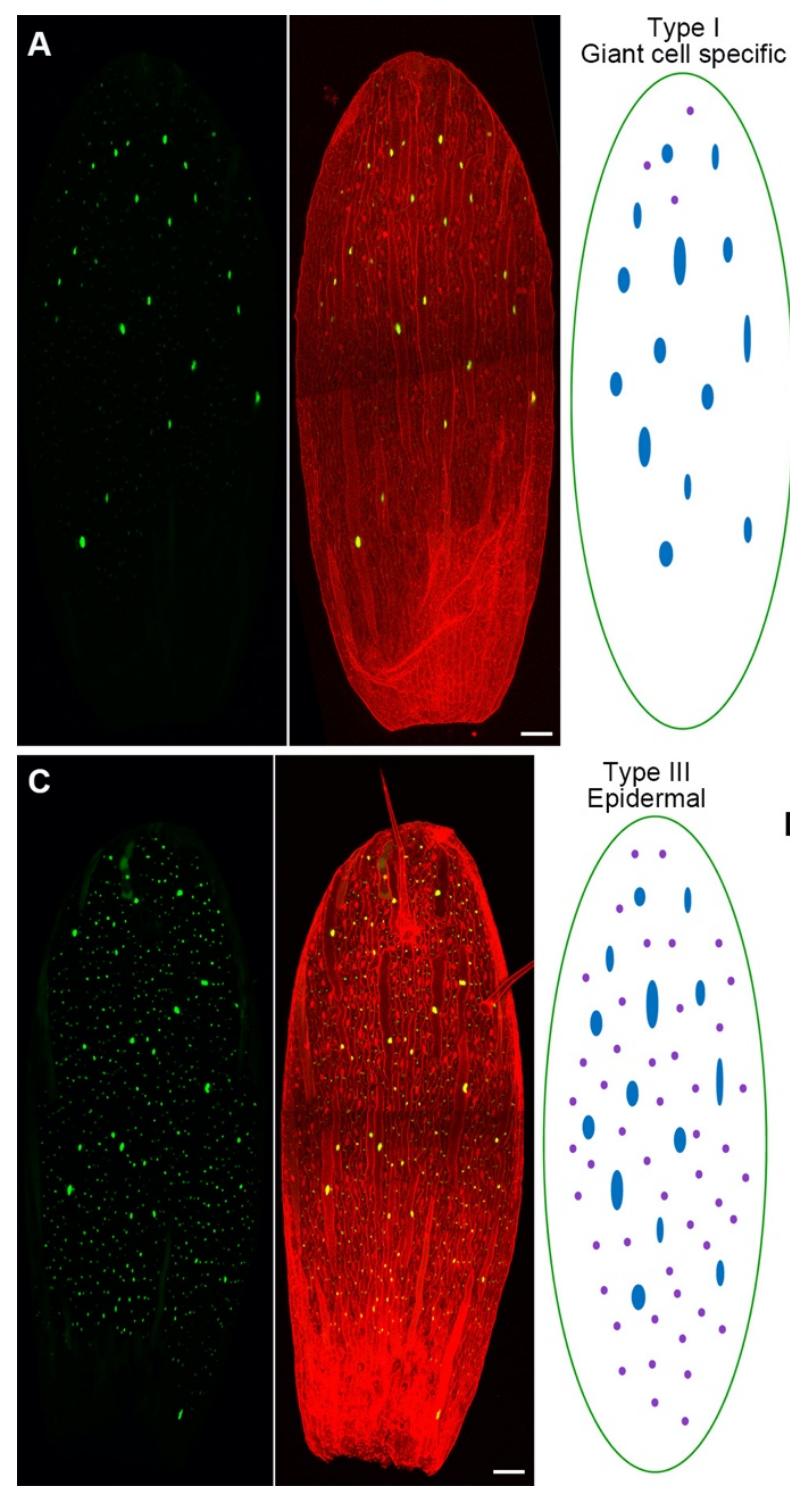

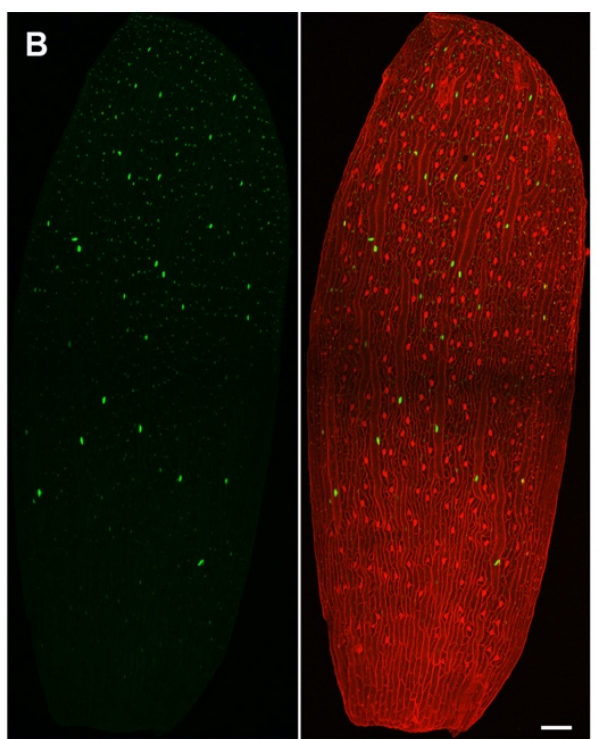

Type II Giant cell enhanced

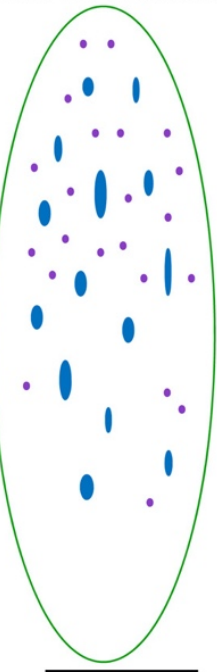

D 100

$100 \%$

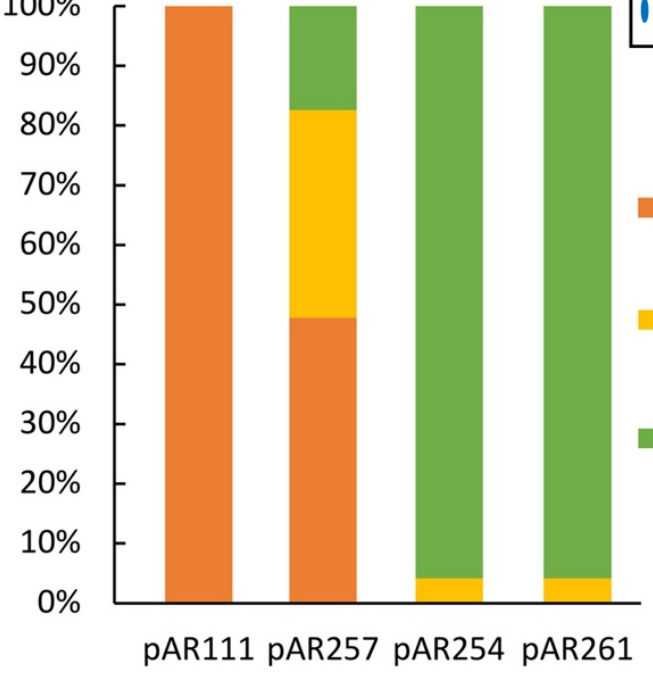

- Small cell

I Giant cell

Type I

specific

Type II

enhanced

Type III
Epidermal

Figure 2. The reporter lines show three types of expression pattern.

(A-C) The three types of expression pattern detected from reporter lines with $p A R 257$ (Region 1-2). Images on the left, $3 \times$ Venus (green) marking the nuclei of cells expressing the reporter; images in the middle, $3 \times$ Venus (green) signals merged with PI (red) stained cell wall signals; images on the right, schematic summarizing the pattern. In type I (giant cell specific) expression pattern, $3 \times$ Venus is expressed mainly in giant cells (A). In type II (giant cell enhanced) expression pattern, $3 \times$ Venus is expressed both in giant cells and in small cells located in the tip part (B). In type III (epidermal) expression pattern, $3 \times$ Venus is expressed broadly throughout the epidermis (C). Scale bars: $100 \mu \mathrm{m}$.

(D) Percentages of the three types of reporter expression patterns observed across different reporter lines. pAR111 (Region 1-2-3-4) sepals all show the type I pattern. pAR254 (Region 2) and pAR261 (Region 2-3) have predominantly type III expression pattern. 
bioRxiv preprint doi: https://doi.org/10.1101/2020.08.28.270454; this version posted November 14,2020 . The copyright holder for this preprint (which was not certified by peer review) is the author/funder, who has granted bioRxiv a license to display the preprint in perpetuity. It is made available under aCC-BY-NC 4.0 International license.

Table 1. Full-genome yeast one-hybrid screen results: high-confidence interactions

\begin{tabular}{|c|c|c|c|}
\hline Gene family & Region 1 & Overlap & Region 2 \\
\hline $\mathrm{C}_{2} \mathrm{C}_{2}$-Dof & $\begin{array}{l}\text { DOF1.8 (AT1G64620) } \\
\text { DOF4.7 (AT4G38000) }\end{array}$ & & \\
\hline TCP & & $\begin{array}{l}\text { TCP2 (AT4G18390) } \\
\text { TCP3 (AT1G53230) } \\
\text { TCP4 (AT3G15030) } \\
\text { TCP19 (AT5G51910) } \\
\text { TCP24 (AT1G30210) }\end{array}$ & $\begin{array}{l}\text { TCP2 (AT4G18390) } \\
\text { TCP3 (AT1G53230) } \\
\text { TCP4 (AT3G15030) } \\
\text { TCP10 (AT2G31070 }\end{array}$ \\
\hline HD-ZIP & & HDG11 (AT1G73360) & $\begin{array}{l}\text { ANL2 (AT4G00730) } \\
\text { GL2 (AT1G79840) } \\
\text { HDG11 (AT1G73360) } \\
\text { PHB (AT2G34710) }\end{array}$ \\
\hline AP2 & $\begin{array}{l}\text { CRF5 (AT3G61630) } \\
\text { DEWAX (AT5G61590) } \\
\text { DREB2 (AT5G05410) } \\
\text { ERF53 (AT2G20880) } \\
\text { ERF14 (AT1G04370) } \\
\text { ESE1 (AT3G23220) } \\
\text { RAP2.4 (AT1G22190) } \\
\text { AT3G57600 } \\
\text { AT1G72570 } \\
\text { AT1G75490 } \\
\text { AT5G18450 } \\
\text { AT5G65130 }\end{array}$ & $\begin{array}{l}\text { AIL5 (AT5G57390) } \\
\text { DEWAX (AT5G61590) } \\
\text { DREB2 (AT5G05410) } \\
\text { EBP (AT3G16770) } \\
\text { ERF1 (AT3G23240) } \\
\text { ERF14 (AT1G04370) } \\
\text { ESE1 (AT3G23220) } \\
\text { ESE2 (AT2G25820) } \\
\text { RAP2.4 (AT1G22190) } \\
\text { RAP2.6 (AT1G43160) } \\
\text { AT1G72570 } \\
\text { AT3G18960 } \\
\text { AT4G33280 } \\
\text { AT5G65130 }\end{array}$ & $\begin{array}{l}\text { AlL5 (AT5G57390) } \\
\text { ANT (AT4G37750) } \\
\text { AT1G04370 } \\
\text { AT1G72570 } \\
\text { AT1G75490 } \\
\text { AT3G16770 } \\
\text { AT3G57600 } \\
\text { AT4G31060 } \\
\text { AT5G05410 } \\
\text { AT5G18450 } \\
\text { AT5G65130 }\end{array}$ \\
\hline ARR & ARR2 (AT3G04280) & $\begin{array}{l}\text { ARR1 (AT3G16857) } \\
\text { ARR3 (AT1G59940) } \\
\text { ARR22 (AT3G04280) }\end{array}$ & ARR22 (AT3G04280) \\
\hline bHLH & AKS1 (AT1G51140) & $\begin{array}{l}\text { LHL2 (AT2G31280) } \\
\text { LHW (AT2G27230) }\end{array}$ & $\begin{array}{l}\text { AKS1 (AT1G51140) } \\
\text { PIF5 (AT3G59060) } \\
\text { PIL5 (AT2G20180) } \\
\text { AT3G57800 }\end{array}$ \\
\hline others & $\begin{array}{l}\text { BBX7 (AT3G07650) } \\
\text { BBX26 (AT1G60250) } \\
\text { E2FC (AT1G47870) } \\
\text { GEBP (AT4G00270) } \\
\text { HB7 (AT2G46680) } \\
\text { LBD18 (AT2G45420) } \\
\text { NAC078 (AT5G04410) }\end{array}$ & $\begin{array}{l}\text { ATCTH (AT2G25900) } \\
\text { BBX27 (AT1G68190) } \\
\text { EIL3 (AT1G73730) } \\
\text { EIN3 (AT3G20770) } \\
\text { EMB2746 (AT5G63420) } \\
\text { GEBP (AT4G00270) } \\
\text { GOA (AT1G31140) } \\
\text { HSFA9 (AT5G54070) } \\
\text { JLO (AT4G00220) } \\
\text { KAN2 (AT1G32240) } \\
\text { MBS1 (AT3G02790) } \\
\text { MYB88 (AT2G02820) } \\
\text { NAC042 (AT2G43000) } \\
\text { SAP (AT5G35770) } \\
\text { SRS4 (AT2G18120) } \\
\text { TCX2 (AT4G14770) } \\
\text { VOZ1 (AT1G28520) } \\
\text { WRKY7 (AT4G24240) } \\
\text { WRKY16 (AT5G45050) } \\
\text { AT1G04500 } \\
\text { AT1G11950 } \\
\text { AT1G14580 } \\
\text { AT1G31040 } \\
\text { AT1G76590 } \\
\text { AT3G07500 } \\
\text { AT4G00390 } \\
\text { AT4G09450 }\end{array}$ & $\begin{array}{l}\text { ATX1 (AT2G31650) } \\
\text { bZIP19 (AT4G35040) } \\
\text { EIL3 (AT1G73730) } \\
\text { HB7 (AT2G46680) } \\
\text { HB30 (AT5G15210) } \\
\text { HB33 (AT1G75240) } \\
\text { WRKY47 (AT4G01720) } \\
\text { AT1G01640 } \\
\text { AT1G55650 } \\
\text { AT3G04450 } \\
\text { AT4G00390 } \\
\text { AT4G08455 }\end{array}$ \\
\hline
\end{tabular}

See also Table S1 

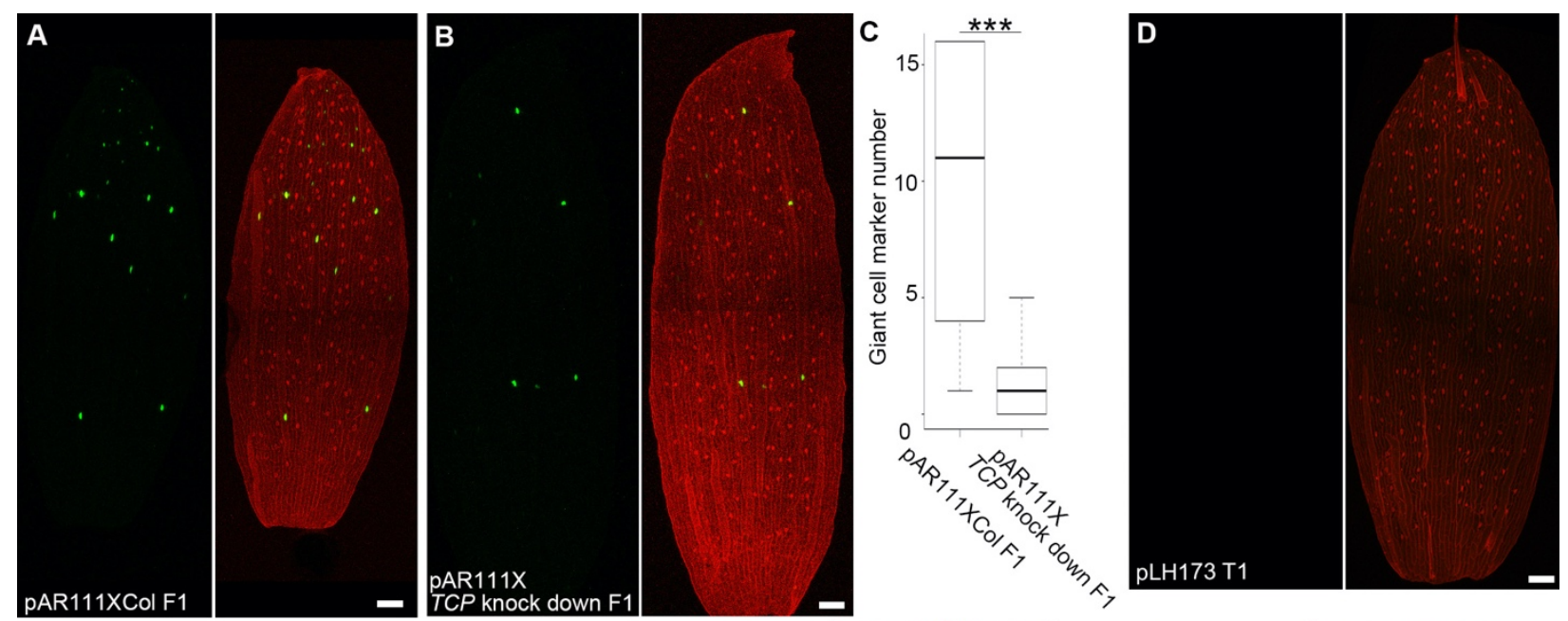

E
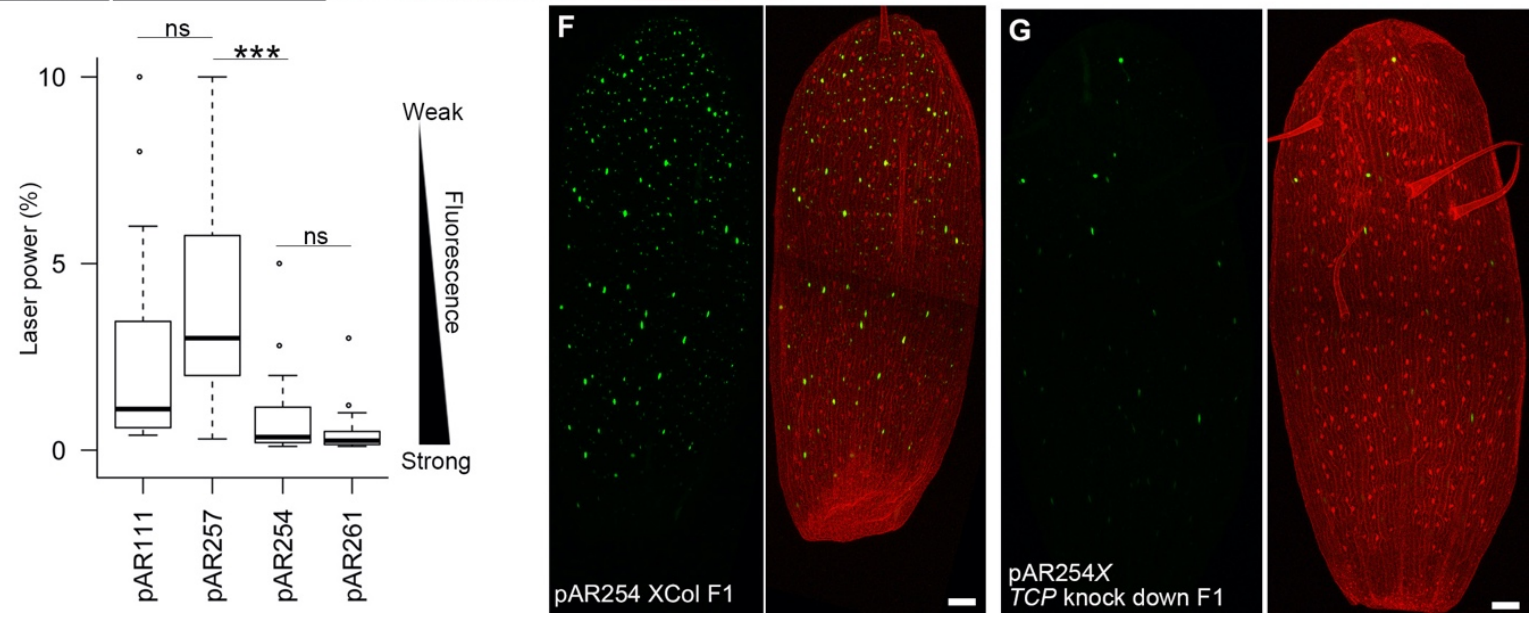

Figure 3. TCP transcription factors promote expression activity.

(A) Confocal images of a sepal from $p A R 111$ and Col-0 (Col) hybrid plants.

(B) Confocal images of a sepal from $p A R 111$ and TCP knock-down (jaw-1D) hybrid plants.

(C) The number of nuclei expressing $3 \times$ Venus in $p A R 111 \times$ Col hybrid sepals and $p A R 111 \mathrm{X}$ TCP knockdown $(j a w-1 D)$ hybrid sepals. The boxes extend from the lower to upper quartile values of the data, with a line at the median. The whiskers extend past 1.5 of the interquartile range. ${ }^{* * *} \mathrm{p}<0.001$, significant difference by two tailed t-test, $\mathrm{p}=9.86 \mathrm{E}-08 ; \mathrm{n}=20$.

(D) Confocal images of a sepal from a $p L H 173$ (all TGGG putative TCP sites mutated in giant cell enhancer fragment 2) T1 plant. Hardly any nuclei expressing $3 \times$ Venus can be detected.

(E) The laser intensity required to saturate the $3 \times$ Venus signal in giant cell for each reporter line. $p A R 257$ needs much higher laser intensity, indicating it has much lower expression level of $3 \times$ Venus. The boxes extend from the lower to upper quartile values of the data, with a line at the median. The whiskers extend past 1.5 of the interquartile range. $n s$, non-significant difference ( $t$ test); $* * * p<0.001$, significant difference by two tailed t-test, $\mathrm{p}=1.07 \mathrm{E}-11 ; \mathrm{n}=17$ for $\mathrm{pAR} 111, \mathrm{n}=22$ for $\mathrm{pAR} 257, \mathrm{n}=24$ for $\mathrm{pAR} 254$, and $\mathrm{n}=24$ for pAR261.

(F) Confocal images of a sepal from a hemizygous $p A R 254$ plant $(p A R 254 \times \mathrm{Col} \mathrm{F1).}$

(G) Confocal images of a sepal from $p A R 254 \times T C P$ knock-down $(j a w-1 D)$ F1 hybrid plants.

Sepals were imaged at the same setting, with 3\% laser power. Scale bars: $100 \mu \mathrm{m}$. See also Figures S3, S4, and S5. 

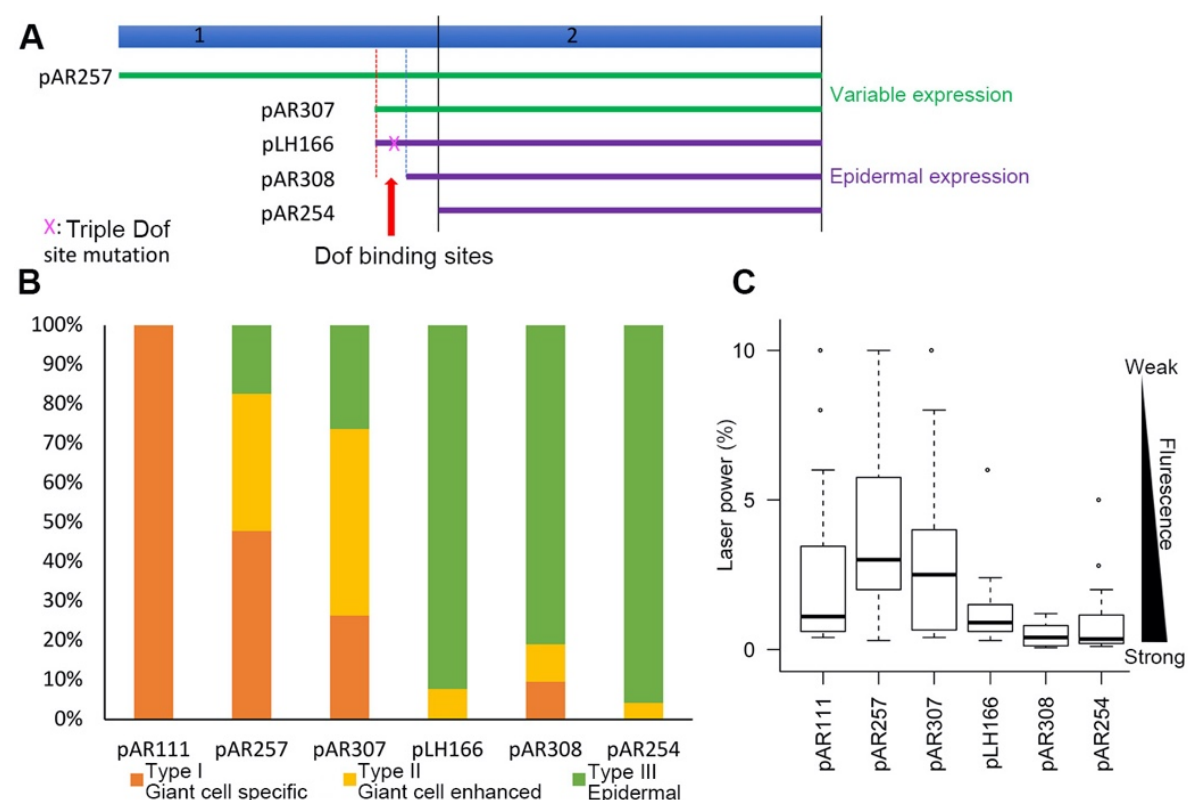

Figure 4. Dof binding sites in Region 1 confer giant cell enhanced activity.

(A) Fine-scale dissecting of Region 1 in the enhancer. Schematics of reporter lines containing different fragments or mutation of Region 1 were shown.

(B) Percentages of the three expression pattern types in different reporter lines. Data for $p A R 111, p A R 254$ and $p A R 257$ were duplicated from Figure 2D for comparison.

(C) The laser intensity required to saturate the $3 \times$ Venus signal in giant cell for each reporter line. The higher laser intensity signifies weaker fluorescence of the reporter. The boxes extend from the lower to upper quartile values of the data, with a line at the median. The whiskers extend past 1.5 of the interquartile range. Data for $p A R 111, p A R 254$ and $p A R 257$ were duplicated from Figure 3E for comparison.

See also Figure S4, S6, and S7. 
bioRxiv preprint doi: https://doi.org/10.1101/2020.08.28.270454; this version posted November 14,2020 . The copyright holder for this preprint (which was not certified by peer review) is the author/funder, who has granted bioRxiv a license to display the preprint in perpetuity. It is made available under aCC-BY-NC 4.0 International license.
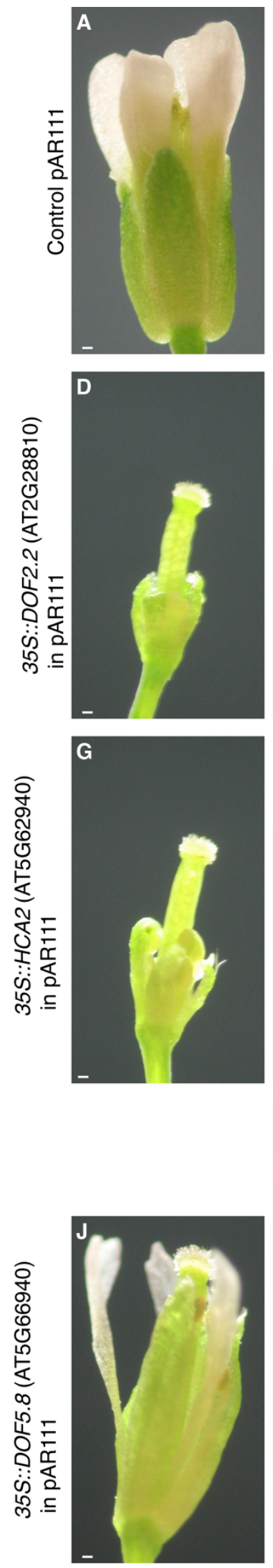

B

E
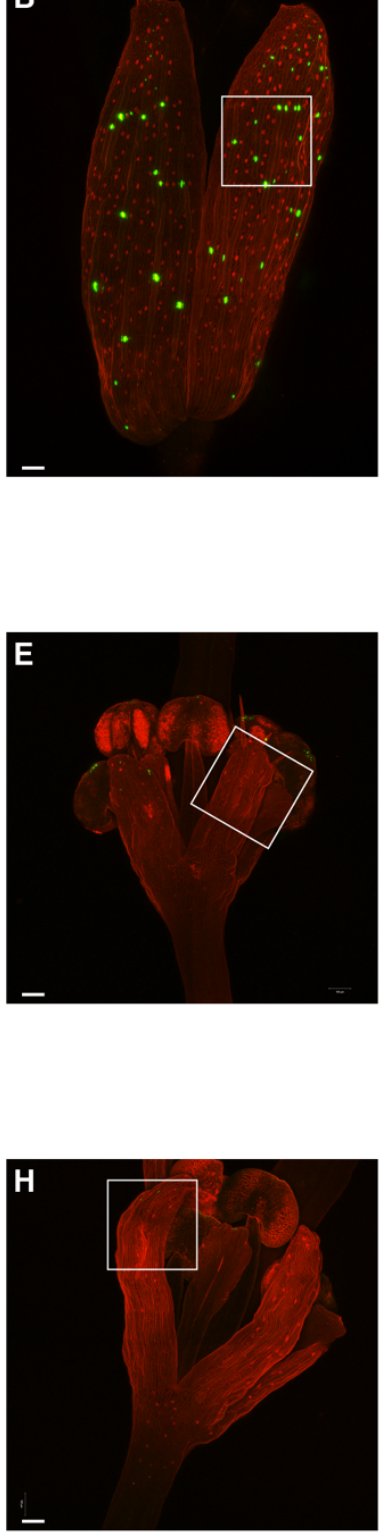

K

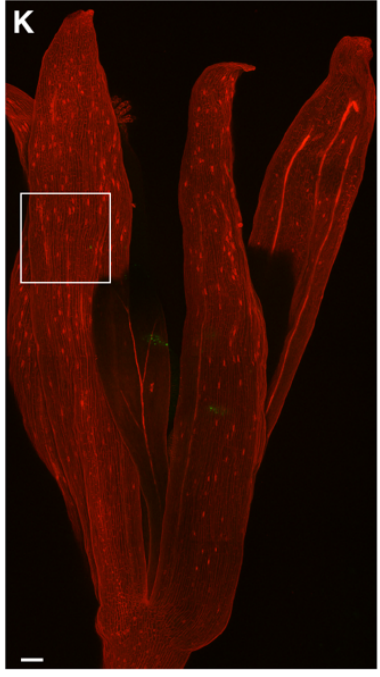

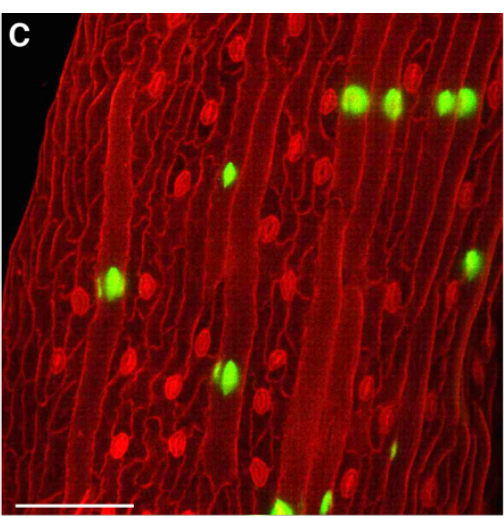
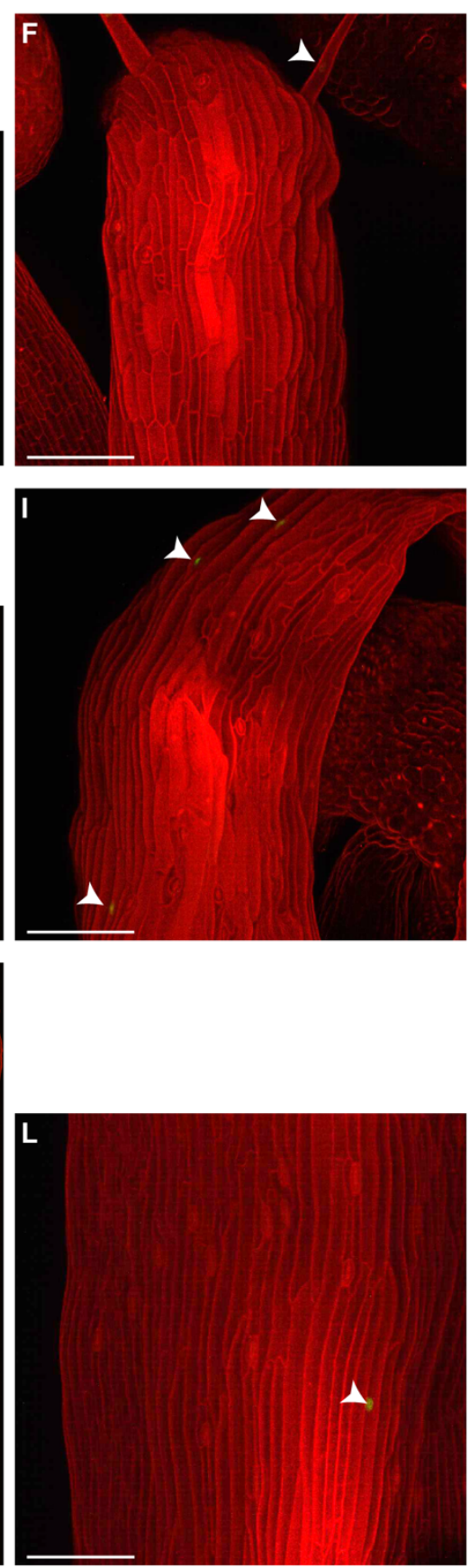
Figure 5. Dof transcription factor overexpression suppresses giant cell enhancer activity.

pAR111 is the full length giant cell enhancer which drives $3 \times$ Venus-N7 expression in giant cells (nuclear localized green signal). Cell walls were stained with PI (red). Arrowheads indicate nuclei expressing weak signal.

(A-C) Flowers from a control pAR111 plant. (A) A dissecting microscope image. (B) A confocal image showing bright $p A R 111$ full length giant cell enhancer reporter signal in giant cell nuclei. (C) Magnification of the white box in $\mathrm{B}$.

(D-F) Flowers from a $p A R 111$ plant expressing $p 35 S:: D O F 2.2$ (AT2G28810). (D) A dissecting microscope image showing stunted sepals, petals, and stamens. (E) A confocal microscope image showing strong repression of the pAR111 giant cell enhancer activity. (F) Magnification of the white box in E.

(G-I) Flowers from $p A R 111$ plant expressing $p 35 S:: H C A 2$ (AT5G62940). (G) A dissecting microscope image showing stunted sepals, petals, and stamens. (H) A confocal microscope image showing strong repression of the $p A R 111$ giant cell enhancer activity. (I) Magnification of the white box in $\mathrm{H}$.

(J-L) Flowers from pAR111 plant expressing p35S::DOF5.8 (AT5G66940). (J) A dissecting microscope image showing the sepals are narrow and highly elongated. (K) A confocal microscope image showing strong repression of the $p A R 111$ giant cell enhancer activity. (L) Magnification of the white box in K. Note that the arrowhead points to expression in a giant cell and that faint transverse walls that appear are in an underlying cell layer.

Scale bars: $100 \mu \mathrm{m}$. Confocal images were taken with the same settings at 3\% laser power. C, F, I, and L were rendered in MorphoGraphX adjusted in Photoshop with auto contrast. See also Figure S6. 
A
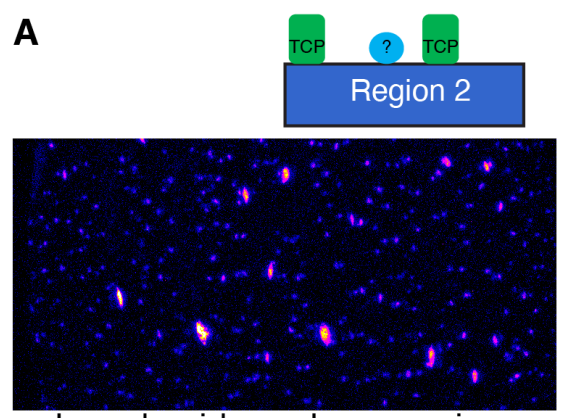

broad epidermal expression

(giant and small cells)
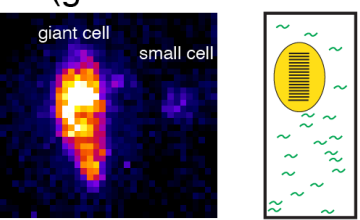

C

$\triangle$ Dofs

TCPs

Others
B

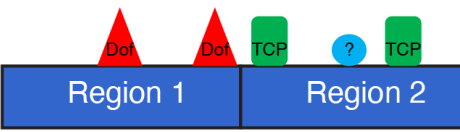

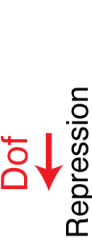

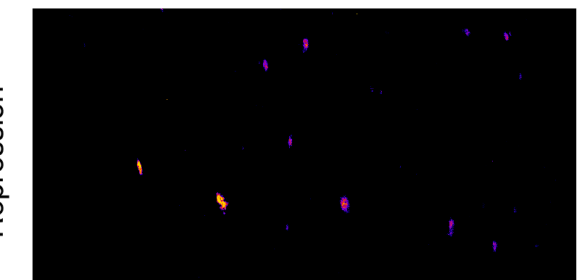

giant cell specific expression
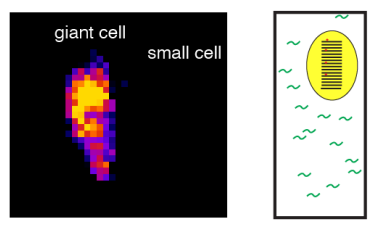

giant cell specific expression

0 intermediate expression

0 epidermal expression

\begin{tabular}{|c|c|c|c|}
\hline Diagrams & Constructs & $\begin{array}{c}\text { Expression } \\
\text { pattern }\end{array}$ & $\begin{array}{c}\text { Expression } \\
\text { level }\end{array}$ \\
\hline & $\begin{array}{c}\text { 35S::Dof in } \\
\text { pAR111 }\end{array}$ & $\begin{array}{l}\text { Largely } \\
\text { repressed }\end{array}$ & low \\
\hline$\square$ & pAR111 & 1 & high \\
\hline 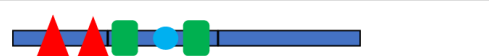 & pAR262 & & low \\
\hline ᄃ & pAR257 & & low \\
\hline & pAR307 & & low \\
\hline & pLH166 & & high \\
\hline & pAR254 & & high \\
\hline & $\begin{array}{l}\text { pAR254 TCP } \\
\text { knock down }\end{array}$ & 0 & low \\
\hline & pAR260 & & \\
\hline & pAR261 & 6 & high \\
\hline$\square$ & pLH173 & \begin{tabular}{|c} 
Essentially no \\
expression
\end{tabular} & very low \\
\hline 57 & $\begin{array}{l}\text { pAR111 TCP } \\
\text { knock down }\end{array}$ & O & low \\
\hline 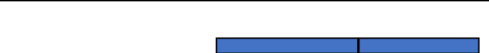 & pAR258 & & no \\
\hline & pAR280 & & no \\
\hline
\end{tabular}


Figure 6. Summary: Giant cell specificity arises from the repression of a broad epidermal expression pattern

In the giant cell enhancer, cell type specificity of expression arises primarily from the combination of two elements: Region 1, an element driving broad epidermal expression, with higher expression levels in giant cells than small cells, and Region 2, an element repressing expression, and making the expression pattern giant cell specific.

(A) Region 2 of the giant cell enhancer drives broad epidermal expression of the reporter. Nevertheless this expression is stronger in giant cells (large, highly endoreduplicated nuclei) than small cells (smaller nuclei) as highlighted by the fire LUT (using FIJI) applied in A. Our evidence suggests that TCP transcription factors (represented as green rectangles) bind to and activate expression via Region 2 of the enhancer. Note that our representation of two green rectangles representing TCPs, is meant to represent a wild type level of binding to the three putative TCP sites we identified, not a precise number of transcription factors bound. Our yeast-one hybrid results suggest that other factors (represented generally as a blue oblong) including HD-ZIP Class IV transcription factors bind to Region 2. We speculate these may be important in either activating epidermal expression or activating stronger expression in giant cells than small cells. One factor that may contribute to the increased expression in giant cells is the increased ploidy of these cells, providing many more copies of the enhancer (as represented in the giant cell with 16C DNA content) and lots of transcripts (represented in green) to drive strong enhancer expression (strong yellow in the nucleus) in comparison to the small diploid cell with few transcripts and low expression in the nucleus.

(B) When combined with Region 1, Region 2 becomes much more giant cell specific as detailed in the results. Our evidence suggests that Dof transcription factors (represented as red triangles) bind to this element and repress expression. Note again, that the number of triangles is meant to convey the wild type occupancy of Dofs bound to Region 1, not an exact number of proteins.

(C) Table summarizing the results of each of our dissection constructs together with site specific mutations and genetic manipulation of TCPs and Dofs. Again, the red triangles, green rectangles, and blue ovals represent relative occupancy, not exact numbers of transcription factors bound to DNA. 
CCTGTCCGCTATATCATGCAAATCCAAATGAAAATGATTTGATTGATGTTACTCTAACTGTAAGA AАAAAGTGCATTATTGAAAACTTCCTTTTTCTCTGTACACAACTACAATAGCCAGAAGCAATTTG TAGGTCATAAAACATTATAATAGATATTTTCTTTTTGGAAAGTTTAACCTCTTTTTCTCCTTAAT TGTTGGGAGTGCAATTGGGTATTTAAGAATGAAGATGAAACTTAGATTCAGGACCATTTTGTGTA GCCACTGACGACAGTCCTTCGTACATAATATTTATGTTTAAGTTGGGTGTATTATAAATTTATAT AАTTAATTATGTATATTGTATAGGTGGAGTAGGACCAATTTAGTCGTCAAAAGATAATGTGCATG AATGATGACAAGAATGCGATATTTTTGGCATGAATCATGATTAATCAATGATGTCAATCAAGATT ACAAATTTATACGAAATGATAGTAAAAAGGTTCAAAAGTCTCTTAATTCTATTACACCAACAAAA AAAAAGTCTCTTCATTCTACCTCACTAATATATGTTTGTTCGGTTTGGATTGTTTTTAAGAGGTC CGAGCCGAGATCCGACTAATTTCTTAATGGATCTAAAACATGATACTAATTTTGACTAACTATGA AAGAGAGAAATATCATCTACAAAATAAAAATTACTAAAAGTTTAAGAAGGTGTTCTAAATAGTTT AGTACAATTTATTAAACTCTTGTGAACCTTTTCTAAATAAAATCTTGTAGTCTTGGTGTTTTCCT AАATATTGTATTTTTAAATTAAAAACTTAATTTTGTCATATTTGAAGATATTTCTCTATACATAA ATAAATATATCTTTCGAGCATACACGAACATTACATTTCTCTGGACAAATCAACATTAGGTTTAT TCAATTGTCGATTTGACAAACGATGAAAGAAAACGAAACCCTACATATCTTTTAAGCATAAGTGA СTCTGTGGTTCATGATCTCTATTTCTGGTTCAACGAACGCAAAAGGTAT

\section{Figure S1. The whole sequence of the giant cell enhancer, related to Figure 1.}

Green: Region 1, 1-208 bp; magenta: Region 2, 209-450 bp; blue: Region 3, 451-760 bp; purple: Region 4, 761-1024 bp. The underlined region is the overlapping region used in the yeast one hybrid assay. 
bioRxiv preprint doi: https://doi.org/10.1101/2020.08.28.270454; this version posted November 14,2020 . The copyright holder for this preprint (which was not certified by peer review) is the author/funder, who has granted bioRxiv a license to display the preprint in perpetuity. It is made available under aCC-BY-NC 4.0 International license.

Table S1. Full-genome yeast one-hybrid screen results: low-confidence interactions, related to Table 1

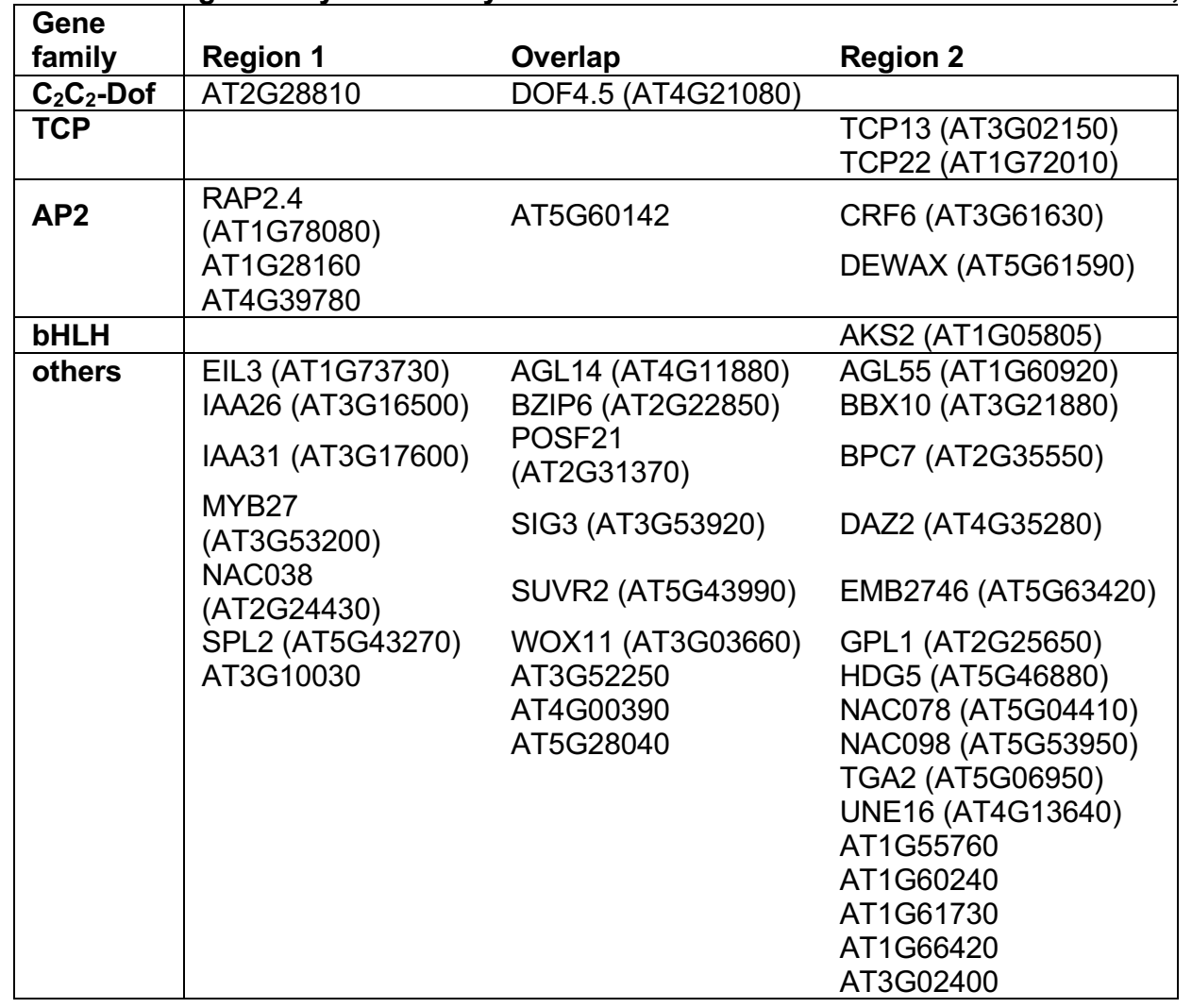



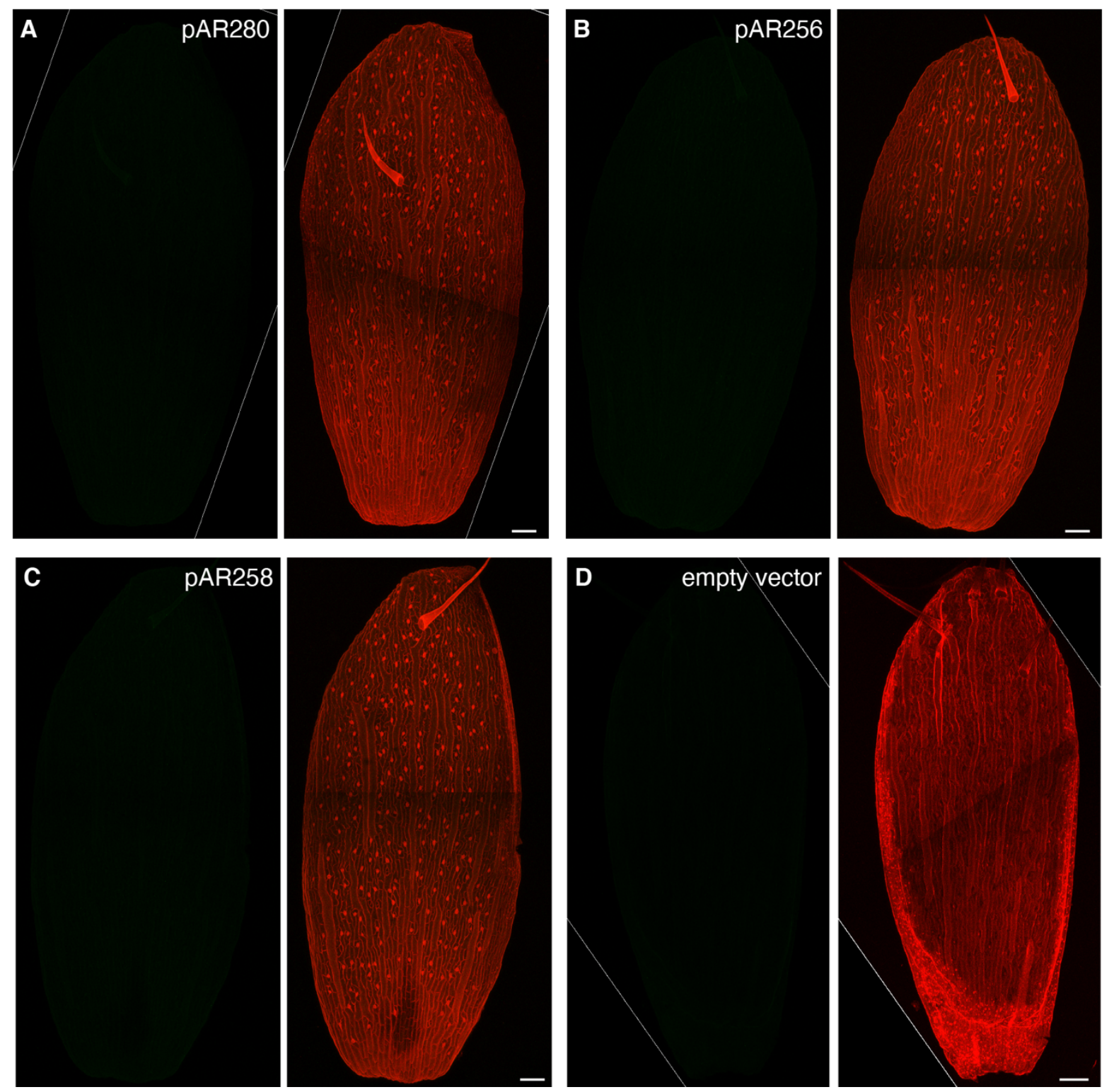

Figure S2. Region 1 alone, Region 4 alone and Regions 3 and 4 together are not sufficient to drive any reporter expression, related to Figure 1.

Confocal images of stage 14 sepals from different reporter lines. Images on the left show $3 \times$ Venus (green) signal marking the nuclei of cells expressing the reporter. Images on the right show $3 \times$ Venus (green) signals merged with PI (red) stained cell walls. Images were taken with $3 \%$ laser power except where noted. Increasing laser power to $40 \%$ did not reveal any expression.

(A) $p A R 280$ Region 1 alone does not drive any reporter expression.

(B) $p A R 256$ Region 4 alone does not drive any reporter expression.

(C) $p A R 258$ Region 3-4 do not drive any reporter expression.

(D) The empty vector $(p S L 12)$ does not drive any reporter expression. Imaged at $2.6 \%$ laser power. Scale bars represent $100 \mu \mathrm{m}$. 


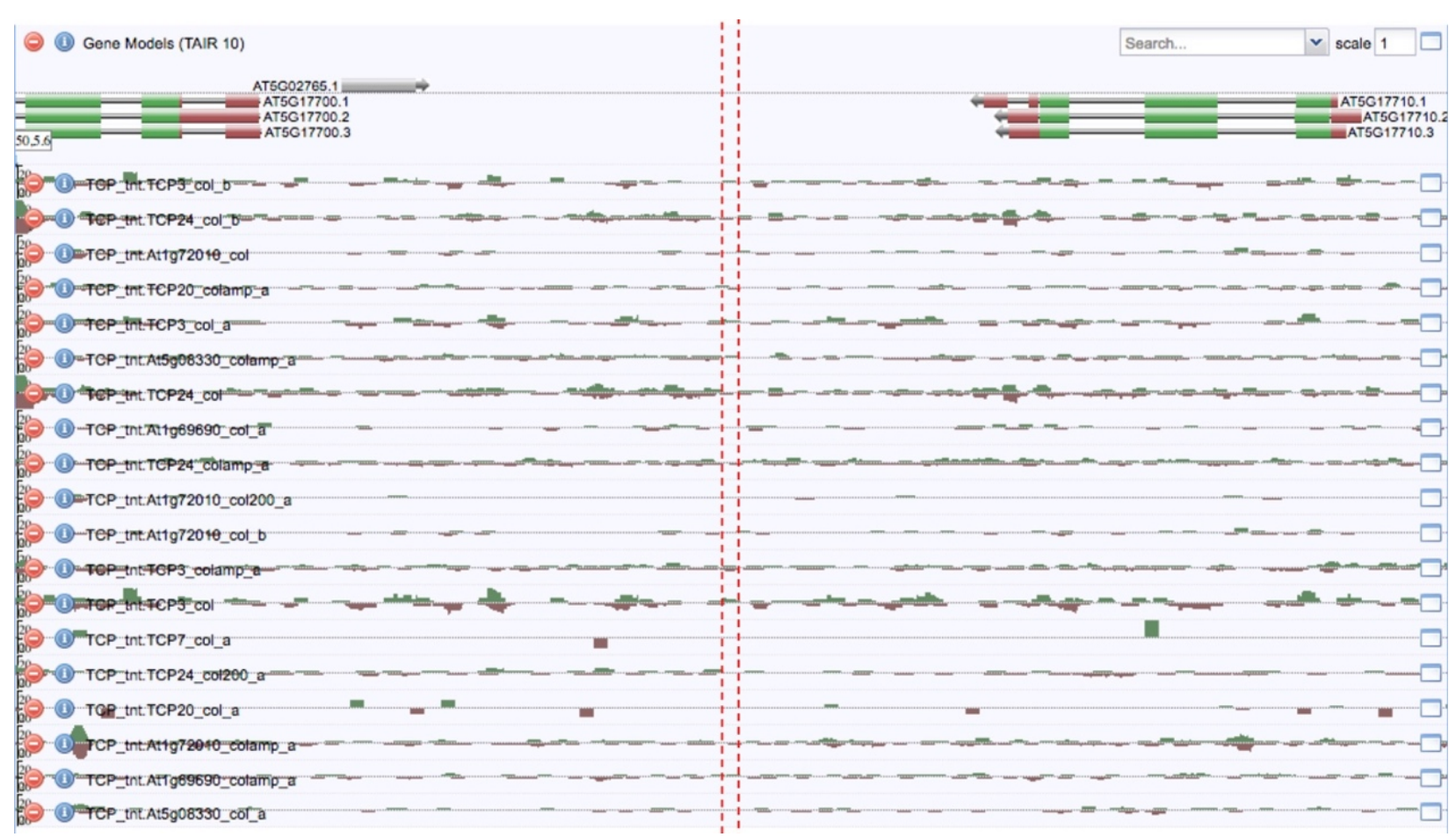

Fig. S3. TCP transcription factors bind to the giant cell enhancer and nearby region, related to Figure 3.

Binding sites of TCP transcription factors in the giant cell enhancer and nearby region. The red dash lines flank the three TCP binding site region in Region 2. Data are from DNA affinity purification sequencing (DAP-seq)

analysis (http:/neomorph.salk.edu/dev/pages/shhuang/dap_web/pages/aj_browsers.php). We observe moderate binding throughout the intergenic region including the region of the enhancer. We speculate that this moderate binding might reflect spatial restriction of binding either to sepals or epidermal cell layers, that would not be accurately captured by DAP-seq. 
AAAAAGTGCATTATTGAAAACTTCCTTTTTCTCTGTACACAACTACAATAGCCAGAAGCAATTTG

Dof binding sites

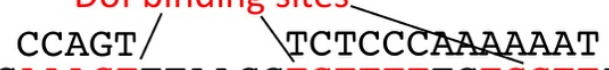

TAGGTCATAAAACATTATAATAGATATTTTCTTTTTGGAAAGTTTAACCTCTTTTTCTCCTTAAT

TCP, binding sites

TGTTGGGAGTGCAATTGGGTATTTAAGAATGAAGATGAAACTTAGATTCAGGACCATTTTGTGTA

TAAA - TCP binding site GCCACTGACGACAGTCCTTCGTACATAATATTTATGTTTAAGTTGGGTGTATTATAAATTTATAT

AАTTAATTATGTATATTGTATAGGTGGAGTAGGACCAATTTAGTCGTCAAAAGATAATGTGCATG

AATGATGACAAGAATGCGATATTTTTGGCATGAATCATGATTAATCAATGATGTCAATC pAR254 PAR308

The mutated sequences shown above the binding sites

Fig. S4. Sequences and locations of the putative Dof binding sites, putative TCP binding sites and different enhancer fragments, related to Figures 3 and 4.

The sequences included in $p A R 307$ (Region 2 + Dof, green line), $p A R 308$ (Region 2 plus, purple line), and pAR254 (Region 2 only, magenta line) are marked with lines below the sequence. The putative Dof binding sites are highlighted with red letters. The putative TCP binding sites are highlighted in blue. The mutated sequences for the putative Dof and TCP binding sites are shown above the original sequences. 


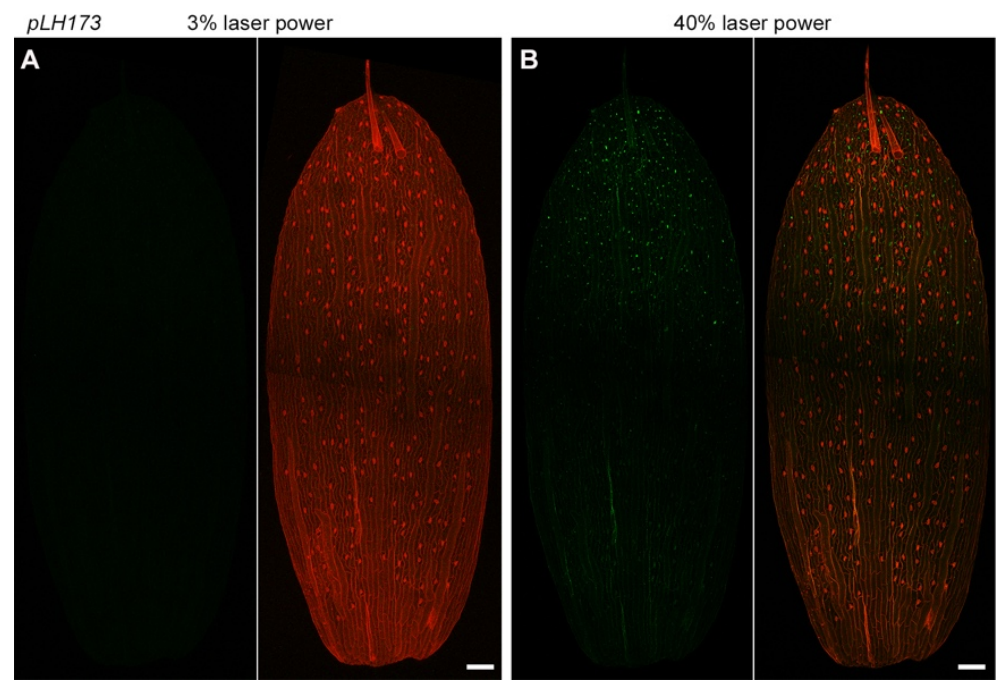

Figure S5. pLH173 sepals expressed weak $3 \times$ Venus in some nuclei, related to Figure 3

Confocal images of a $\mathrm{pLH} 173$ sepal imaged with 3\% (A) and 40\% (B) laser power. With 3\% laser power, hardly any $3 \times$ Venus could be observed on $p L H 173$ sepal epidermis. With laser power increased to $40 \%$, some nuclei at the sepal tip expressed weak $3 \times$ Venus. Images on the left, $3 \times$ Venus (green) marking the nuclei of cells expressing the enhancer reporter; Images on the right, $3 \times$ Venus (green) signals merged with PI (red) stained cell wall signals. A was duplicated from Fig.3D for comparison. 
bioRxiv preprint doi: https://doi.org/10.1101/2020.08.28.270454; this version posted November 14,2020 . The copyright holder for this preprint (which was not certified by peer review) is the author/funder, who has granted bioRxiv a license to display the preprint in perpetuity. It is made available under aCC-BY-NC 4.0 International license.

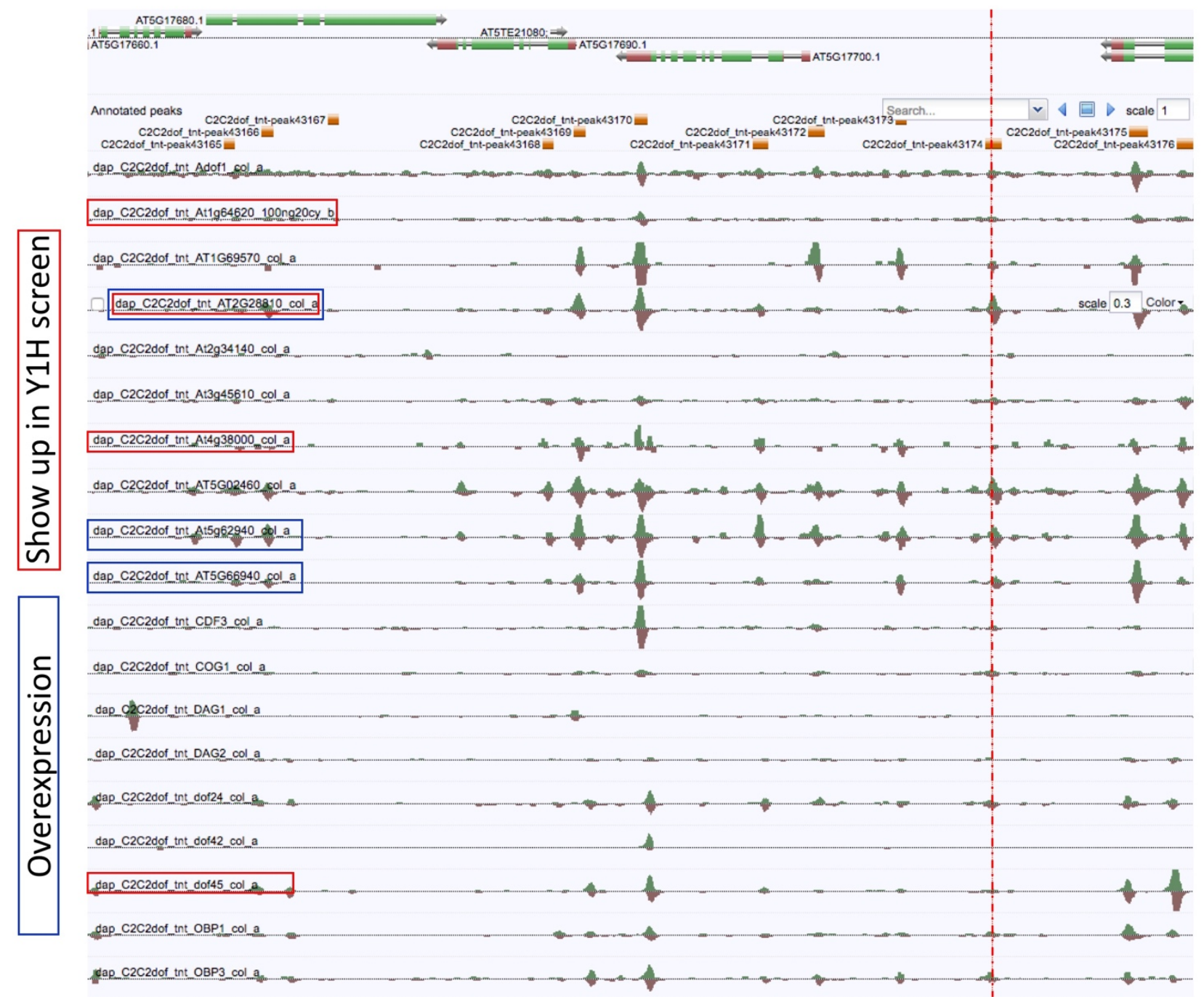

Figure S6 Binding sites of Dof transcription factors in the giant cell enhancer region and nearby, related to Figure 6.

Results by DAP-seq. Dof transcription factors framed in red were identified in the yeast one-hybrid (Y1H) assay in this study; framed in blue were overexpressed in $p A R 111$ Arabidopsis. The red dash line marks the Dof binding site region. 
bioRxiv preprint doi: https://doi.org/10.1101/2020.08.28.270454; this version posted November 14, 2020. The copyright holder for this preprint (which was not certified by peer review) is the author/funder, who has granted bioRxiv a license to display the preprint in perpetuity. It is made available under aCC-BY-NC 4.0 International license.

A_thaliana
A_lyrata
C_hirsuta
B_rapa_ch_A10
S-irio-
E_salsugineum
S_parvula
B_rapa_ch_A02
A_thaliana
A_lyrata
C_hirsuta
B_rapa_ch_A10
S_irio-
E_salsugineum
S_parvula
B_rapa_ch_A02

A thaliana

A-lyrata

Chirsuta

B_rapa_ch_A10

s-irio

E_salsugineum

S_parvula

B_rapa_ch_A02

A_thaliana

A-lyrata

C-hirsuta

B_rapa_ch_A10

s-irio

E_salsugineum

S-parvula

B_rapa_ch_A02

A_thaliana

A-lyrata

Chirsuta

B_rapa_ch_A10

$s_{-}^{-}$irio

$\mathrm{E}^{-}$salsugineum

S_parvula

B_rapa_ch_A02

A_thaliana

A lyrata

C-hirsuta

B_rapa_ch_A10

s-irio

$E^{-}$salsugineum

S parvula

B_rapa_ch_A02

A_thaliana

A-lyrata

C_hirsuta

B_rapa_ch_A10

$s^{-}$irio

E_salsugineum

s_parvula

B_rapa_ch_A02

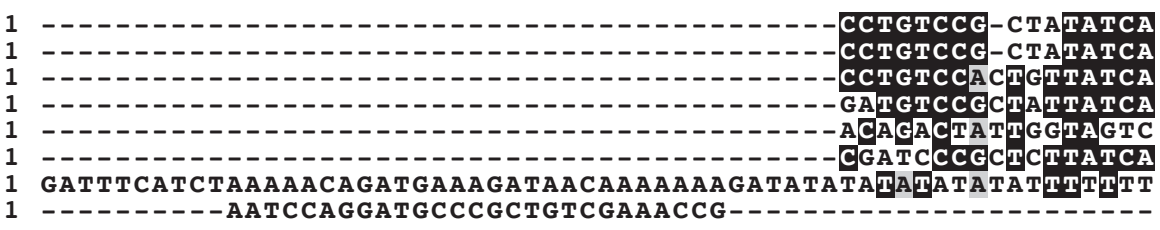

$\begin{array}{ll}17 & T \\ 17 & T \\ 18 & T \\ 18 \\ 18 \\ 18 \\ 61 \\ 28\end{array}$

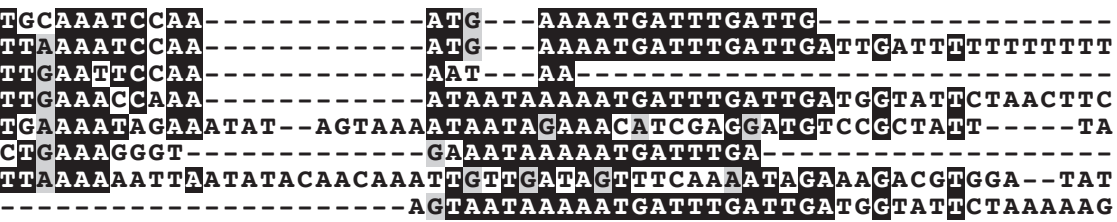

46
62
34
66
71
46
19
66

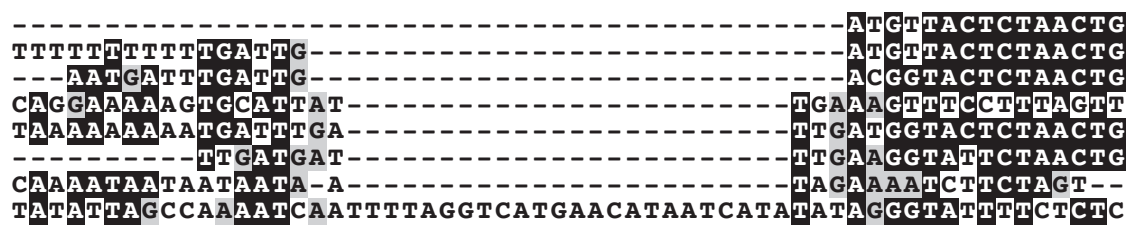

61

93

62

102
107

107
72

72
152

152 - 126 -

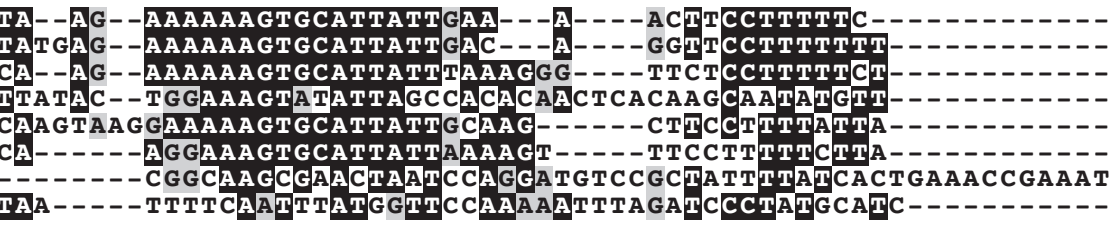

97

132

148

149

149

20

170

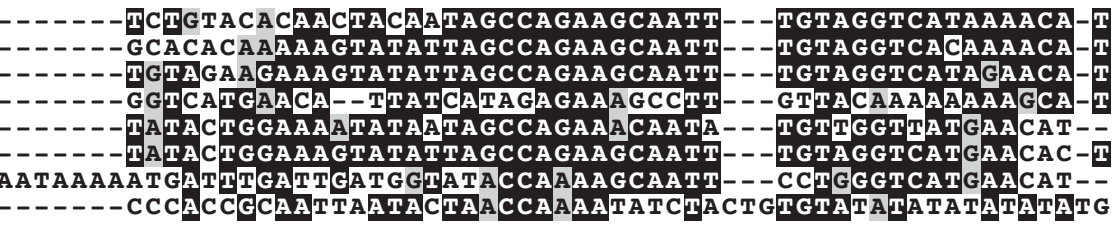

146
181
151
195
197
158
259
223

TATA ATAGAT ATTTTCTTTTT-

pAR307 Dof

Dof Dof

TATCATAGTCATTTTTCTGA--.-- AATT-

TATCATAGTTTTTTTTTGGTTCT----GAAATT-----AAAAATTATGTC

CATCAAAGATTTTTTTTCTC- T------ GA---- AAATTAATATGT

TATCATAGAGCTTTCTTTTT-TT----CTCTGA----AAGTTTAATTATTTTTTTTTC

ATCATAGAGGTTTTMATTTTTCTTTTTGTCTGAAAT-TTTGGTTTAAATCCTC CCTI

GATCATAGAGTTTTTTTTTCTI-- TGCTCTGAAAT-TTTAATTTATGCTTCTTTTTT

TATCTACATAATTTATTAC-TATTTAGACCGCACC CAATGGTCTCCTATGTTTIACTTT pAR308 TCP pAR254TCP

190 CTTAATTGTTGGAGTGCAATTGGTA--- TTTAAGAATGAAGATGAAACTTAGATTCA

227 CTTAATTGCT G GAGTCAATTGGGTA---TTTAAGAATGAAGATGAAGCTTTAGG--

202 CCTTAATTGTTTGGTGCAATTGGTA---TTTAAGAATGAATATGAAACGTAGGTTAT

240 CCTAACTGTTGTGGTGCAATTGGGTA--- TTTATGAATGAATATGAAATTAGGTTCA

247 TTTAAATGTTCTGGTGCAATTGAGTA--- TTTAAGAATGAATATGAACGTAGGTTC-A

217 AATTAATTATTCTGGTCCAGTTGGGTATTAATTAAGAACGAATATGAAACGTAGGTTCA

315 GTAGCTCTTAATTATTGTGGTGCAATAGGTATTMAGAATGA---ATATGAATAGGTTCA

282 TTTTCTCTTATATGAAGCAATTGGTA-- TTAAAGTATGAATATGAAATGTA-TGTCA 


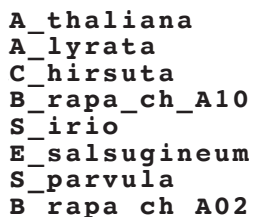

B_rapa_ch_AO2

A_thaliana

A-lyrata

C-hirsuta

B_rapa_ch_A10

$s_{-}^{-}$irio

$E^{-}$salsugineum

S_parvula

B_rapa_ch_AO2

A_thaliana

A-lyrata

C_hirsuta

B_rapa_ch_A10

$s_{-}^{-}$irio

$E^{-}$salsugineum

S-parvula

B_rapa_ch_A02

A_thaliana

A-lyrata

C_hirsuta

B_rapa_ch_A10

$s^{-}$irio

$E_{-}^{-}$salsugineum

S_parvula

B_rapa_Ch_A02

A_thaliana

A_lyrata

C-hirsuta

B_rapa_ch_A10

$s_{-}^{-}$irio

E_salsugineum

S-parvula

B_rapa_ch_A02

A_thaliana

A-lyrata

Chirsuta

B_rapa_ch_A10

$s_{-}^{-}$rio

$E_{-}^{-}$salsugineum

S_parvula

B_rapa_ch_A02

pAR307 pAR308 pAR254

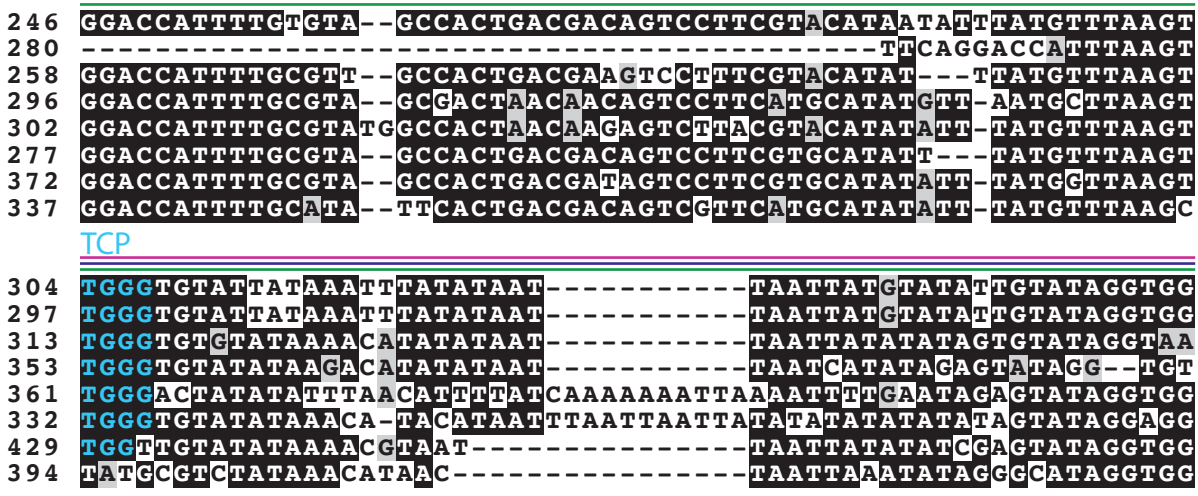

353

346

362

400

421

391

438

412

405

419

458

479

532

432

GTAGGACCAATT TAGTCGTAAAAGATAATG-GCATGAATGATGACAAGAATGCGATA AGTAGGACCAATT TAGTCGTCAAAAGATAATGT-GCATGAATGATGACAAGAATGCGATA GTAGGACCAAAGTCATCAAAA-- GCTAATGTGCATTGAATCATGTAAAGAATGCGATG AGTAGGACCAATAAGC-AGTAAAAAGATAATA-TGCATGAATCATGATATGAAAGCAATG AGTAGGACCAATAAGT-AATCAAAAGATAATA-TTCACGAATCATGATACGATTGCGATG GTAGGACCAGTATAAGTAGTCAAAAGATAATATGCATGAATCATGATAAGAATGCGATG CTAGGGCCAATAAGT-GGTCAAAAGATAATT-TGCATGAATCGTTATAAGAATGCGATG AGCAGGACCAATAAGT-AGTCAAAAGATAATA-TGCATAAATCATGATA-AAATGCGATG

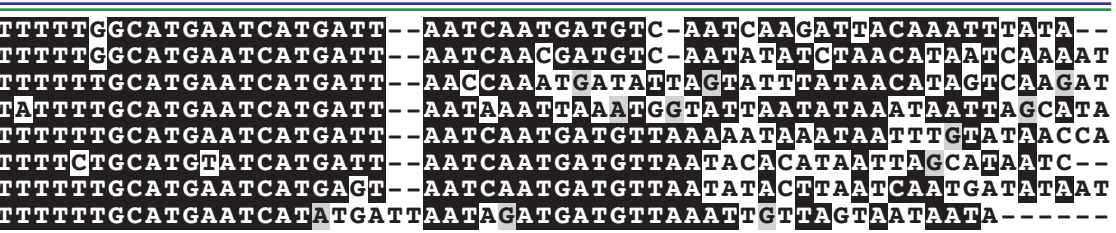

467

462

TA-TATATTT-----

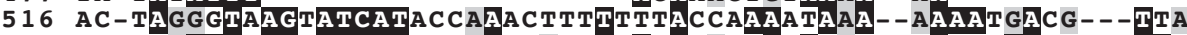

537 ATATTAATTAAGTATCATACAAATGATATTAAAAACCAAACGC--TACTTAA-C-- TCT

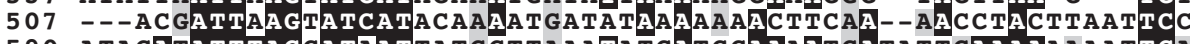

590 ATACATATTTAGCATAATTATCTTAAATATCATCCAAAАTGATATTGAAAAAAAATTCA

549 ---CATATTTAGCATCATCATGATTAAGTATAATTCAAAATGAGATTAAAAA---- TCG

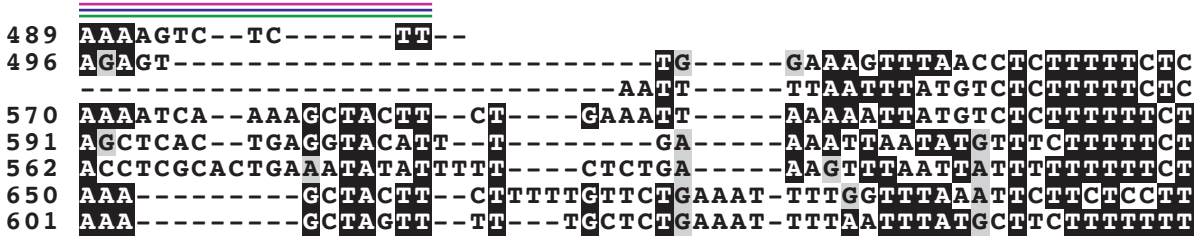

Figure S7 Conservation of Regions 1 and 2 of the giant cell enhancer across Brassicaceae species, related to Figure 4.

Clustal omega sequence alignment of the giant cell enhancer Region 1-2 from Arabidopsis thaliana with Arabidopsis lyrata, Cardamine hirsuta, Sisimbrium irio, Eutrema salsugineum, Schrenkiella parvula (previously Thellungiella parvula) and Brassica rapa. Although Brassica rapa is a diploid, it underwent genome duplication during evolution, so there are two regions on chromosomes A10 and A02 which both align to the giant cell enhancer. The sequences included in $p A R 307$ (Region $2+$ Dof, green line), $p A R 308$ (Region 2 plus, purple line), and pAR254 (Region 2 only, magenta) are annotated with lines above the sequence. The putative Dof binding sites predicted in Arabidopsis thaliana and their conserved counterparts are highlighted with red letters. The putative TCP binding sites and their conserved counterparts are highlighted with aqua letters. 
Table S2: Giant cell enhancer dissection constructs

\begin{tabular}{|c|c|c|c|c|}
\hline $\begin{array}{l}\text { Plant } \\
\text { Construct }\end{array}$ & Region of enhancer & $\begin{array}{l}\text { Forward } \\
\text { primer }\end{array}$ & $\begin{array}{l}\text { Reverse } \\
\text { primer }\end{array}$ & Entry clone \\
\hline pAR111 & $\begin{array}{l}\text { Full length (Region 1-2-3-4) } \\
1-1024 \mathrm{bp}\end{array}$ & oAR214 & oAR215 & $\begin{array}{l}\text { NA (Roeder } \\
\text { et al., 2012) }\end{array}$ \\
\hline pAR262 & $\begin{array}{l}\text { Region 1-2-3 } \\
1-760 \mathrm{bp}\end{array}$ & oAR500 & oAR215 & pSL8 \\
\hline pAR257 & $\begin{array}{l}\text { Region } 1-2 \\
1-449 \mathrm{bp}\end{array}$ & oAR497 & oAR215 & pSL4 \\
\hline pAR260 & $\begin{array}{l}\text { Region 2-3-4 } \\
207-1024 \text { bp }\end{array}$ & oAR214 & oAR498 & pSL7 \\
\hline pAR261 & $\begin{array}{l}\text { Region 2-3 } \\
207-760 \mathrm{bp}\end{array}$ & oAR500 & oAR498 & pSL8 \\
\hline pAR254 & $\begin{array}{l}\text { Region } 2 \\
207-499 \mathrm{bp}\end{array}$ & oAR497 & oAR498 & pSL1 \\
\hline pAR258 & $\begin{array}{l}\text { Region 3-4 } \\
450-1024 \mathrm{bp}\end{array}$ & oAR214 & oAR501 & pSL5 \\
\hline pAR256 & $\begin{array}{l}\text { Region } 4 \\
761-1024 \text { bp }\end{array}$ & oAR214 & oAR499 & pSL3 \\
\hline pAR280 & $\begin{array}{l}\text { Region } 1 \\
1-208 \mathrm{bp}\end{array}$ & oAR532 & oAR215 & pAR278 \\
\hline pLH173 & $\begin{array}{l}\text { Region } 2+\text { with } 3 \text { putative } \\
\text { TCP sites mutated (oAR630- } \\
\text { oAR631 used to mutate third } \\
\text { TCP site) } \\
190-449 \text { bp }\end{array}$ & oAR497 & oAR612 & pDR9 \\
\hline pAR307 & $\begin{array}{l}\text { Region2 with Dof region } \\
167-449 \mathrm{bp}\end{array}$ & oAR497 & oAR556 & pAR299 \\
\hline pLH166 & $\begin{array}{l}\text { Region } 2 \text { with } 3 \text { putative Dof } \\
\text { sites mutated } \\
167-449 \mathrm{bp}\end{array}$ & oAR497 & oLH412 & pLH164 \\
\hline pAR308 & $\begin{array}{l}\text { Region } 2+\text { (without Dof } \\
\text { region) } 190-449 \mathrm{bp}\end{array}$ & oAR497 & oAR609 & pAR301 \\
\hline
\end{tabular}

Associated with Methods 
Table S3: Primer sequences

\begin{tabular}{|l|l|l|}
\hline Primer & Sequence & Purpose \\
\hline oAR214 & CACCTCGAGataccttttgcgttcgttgaacca & Forward primer for Region 4 \\
\hline oAR215 & GCTCGAGcctgtccgctatatcatgcaaatc & Reverse primer for Region 1 \\
\hline oAR497 & CACCgattgacatcattgattaatcatg & Forward primer for Region 2 \\
\hline oAR498 & caattgggtatttaagaatgaag & Reverse primer for Region 2 \\
\hline oAR499 & tgtagtcttggtgttttcctaaat & Reverse primer for Region 4 \\
\hline oAR500 & CACCagattttatttagaaaaggttcacaag & Forward primer for Region 3 \\
\hline oAR501 & aagattacaaatttatacgaaatgatag & Reverse primer for Region 3 \\
\hline oAR505 & CCTCGAGatcaacaagtttgtacaaaaaagct & Forward primer for Gateway sequence with $\mathrm{XhoI}$ \\
\hline oAR532 & tgcactcccaacaattaagg & Forward primer for Region 1 \\
\hline oAR556 & ggaaagtttaacctcttttctcc & Reverse primer for overlap region \\
\hline oAR557 & CACCagtggctacacaaaatggtcc & Forward primer for overlap region \\
\hline oAR609 & cttaattgttgggagtgcaattgggtatttaagaatgaagatgaaac & Reverse primer for Region 2+ without Dof \\
\hline oAR612 & cttaattgttAAAagtgcaattAAAtatttaagaatgaagatgaaac & $\begin{array}{l}\text { Primer for mutating two putative TCP sites } \\
\text { (compare with oAR609) }\end{array}$ \\
\hline oAR630 & cgtacataatatttatgtttaagttAAAtgtattataaatt & Primer for mutating third putative TCP site \\
\hline oAR631 & aatttataatacaTTTaacttaaacataaatattatgtacg & Primer for mutating third putative TCP site \\
\hline oLH412 & ggCCagtttaacctctCCCAAAAAAtaattgttgggagtg & Primer for mutating 3 putative Dof sites \\
\hline oXQ6 & CGGTACCatcaaccactttgtacaagaaagct & Reverse primer for Gateway sequence with $\mathrm{KpnI}$ \\
\hline
\end{tabular}

Capital letters in primers indicate bases that do not match the template sequence, whereas lower case

letters indicate bases that do match the template sequence. Associated with Methods

Table S4: Yeast one hybrid constructs

\begin{tabular}{|l|l|l|l|l|}
\hline $\begin{array}{l}\text { Yeast } \\
\text { Construct }\end{array}$ & Region of enhancer & $\begin{array}{l}\text { Forward } \\
\text { primer }\end{array}$ & $\begin{array}{l}\text { Reverse } \\
\text { primer }\end{array}$ & Entry clone \\
\hline pAR276 & $\begin{array}{l}\text { Region 1 } \\
1-208 \mathrm{bp}\end{array}$ & oAR215 & oAR532 & pAR278 \\
\hline pAR275 & $\begin{array}{l}\text { Region 2 } \\
207-499 \mathrm{bp}\end{array}$ & oAR498 & oAR497 & pSL1 \\
\hline pAR277 & $\begin{array}{l}\text { Overlap of junction } \\
207-499 \mathrm{bp}\end{array}$ & oAR557 & oAR556 & pAR279 \\
\hline
\end{tabular}

Associated with Methods 